\title{
Uniform Trade Rules for Uncleared Markets *
}

\author{
Özgür Kıbrıs $\quad$ Serkan Kü̧̈ükş̧enel ${ }^{\ddagger}$
}

June 30, 2006

\begin{abstract}
We analyze markets in which the price of a traded commodity is such that the supply and the demand are unequal. Under standard assumptions, the agents then have single peaked preferences on their consumption or production choices. For such markets, we propose a class of Uniform Trade rules each of which determines the volume of trade as the median of total demand, total supply, and an exogenous constant. Then these rules allocate this volume "uniformly" on either side of the market. We evaluate these "trade rules" on the basis of some standard axioms in the literature. We show that they uniquely satisfy Pareto optimality, strategy proofness, no-envy, and an informational simplicity axiom that we introduce. We also analyze the implications of anonymity, renegotiation proofness, and voluntary trade on this domain.
\end{abstract}

JEL Classification Numbers: D5, D6, D7

Keywords: market disequilibrium, trade rule, efficiency, strategy proofness, anonymity, no-envy, renegotiation proofness, voluntary trade

*We gratefully acknowledge İpek Gürsel Tapkı for a very useful observation. We also thank William Thomson, Tayfun Sönmez, Utku Ünver, and Anirban Kar as well as the seminar participants at Sabanc1 University, Koç University, ASSET 2004, SED 2004, and the Murat Sertel Memorial Conference on Economic Theory for their comments and suggestions on an earlier version of this paper.

${ }^{\dagger}$ Corresponding author: Faculty of Arts and Social Sciences, Sabancı University, 34956, Orhanll, Tuzla, İstanbul, Turkey. Tel: +90-216-483-9267. Fax: +90-216-483-9250. E-mail: ozgur@sabanciuniv.edu.

${ }^{\ddagger}$ Division of the Humanities and Social Sciences, California Institute of Technology, e-mail: serkank@hss.caltech.edu 


\section{Introduction}

We analyze markets in which the price of a traded commodity is fixed at a level where the supply and the demand are unequal. This phenomenon is observed in many markets, either because the price adjustment process is slow, such as in the labor market, or because the prices are controlled from outside the market (e.g. by the state), such as in health, education, or agricultural markets. It is conceptualized in the idea of market disequilibrium which has been particularly central in Keynesian economics after Clower (1965) and Leijonhufvud (1968) and starting in the early 1970's, which has led to the birth of a literature that enriches the rigorous market-clearing models of the Walrasian theory to encompass nonclearing markets and imperfect competition. For a review of this literature, see Bénassy (1993). For textbook presentations of such models, see Bénassy $(1982,2002){ }^{1}$

A central component of these enriched models is an institution (hereafter, a trade rule) that specifies how transactions are made in a nonclearing market. ${ }^{2}$ In this paper, we axiomatically evaluate trade rules on the basis of some standard properties. ${ }^{3}$

In our model, a set of producers face demand from a set of consumers (who might be individuals as well as other producers that use the traded commodity as input). We assume that the individuals have strictly convex preferences on consumption bundles. They thus have single-peaked preferences on the boundary of their budget sets, and therefore, on their consumption of the commodity in question. Similarly, we assume that the producers have strictly convex production sets. Their profits are thus single-peaked in their output or input. Due to these observations, our paper is also related to earlier studies on single-peaked preferences. $^{4}$

\footnotetext{
${ }^{1}$ Bénassy states that the objective of this literature is to construct "a synthetic paradigm within which ideas (both classical and Keynesian) can be rigorously debated on a common scientific ground". His 1982 and 2002 books present a wide range of models (including extensions of dynamic stochastic general equilibrium models) and use them to rigorously discuss issues such as involuntary unemployment, endogenous growth, policy activism, or the optimal mixture of monetary and fiscal policies.

${ }^{2}$ Note that such an institution is not necessary in a Walrasian model that explicitly assumes equilibrium; there, each agent receives precisely his Walrasian demand.

${ }^{3}$ Though Bénassy (2002) discusses some properties a good trade rule should satisfy (such as Pareto optimality, voluntary trade, and strategy proofness), he refrains from an axiomatic analysis. Instead, he fixes a trade rule that uniformly rations the long side of the market and uses it throughout the rest of his analysis. For a characterization of this rule, please see Remark 3.

${ }^{4}$ For a firm $s$, the preference relation $R_{s}$ is an ordinal representation of how it compares two production
} 

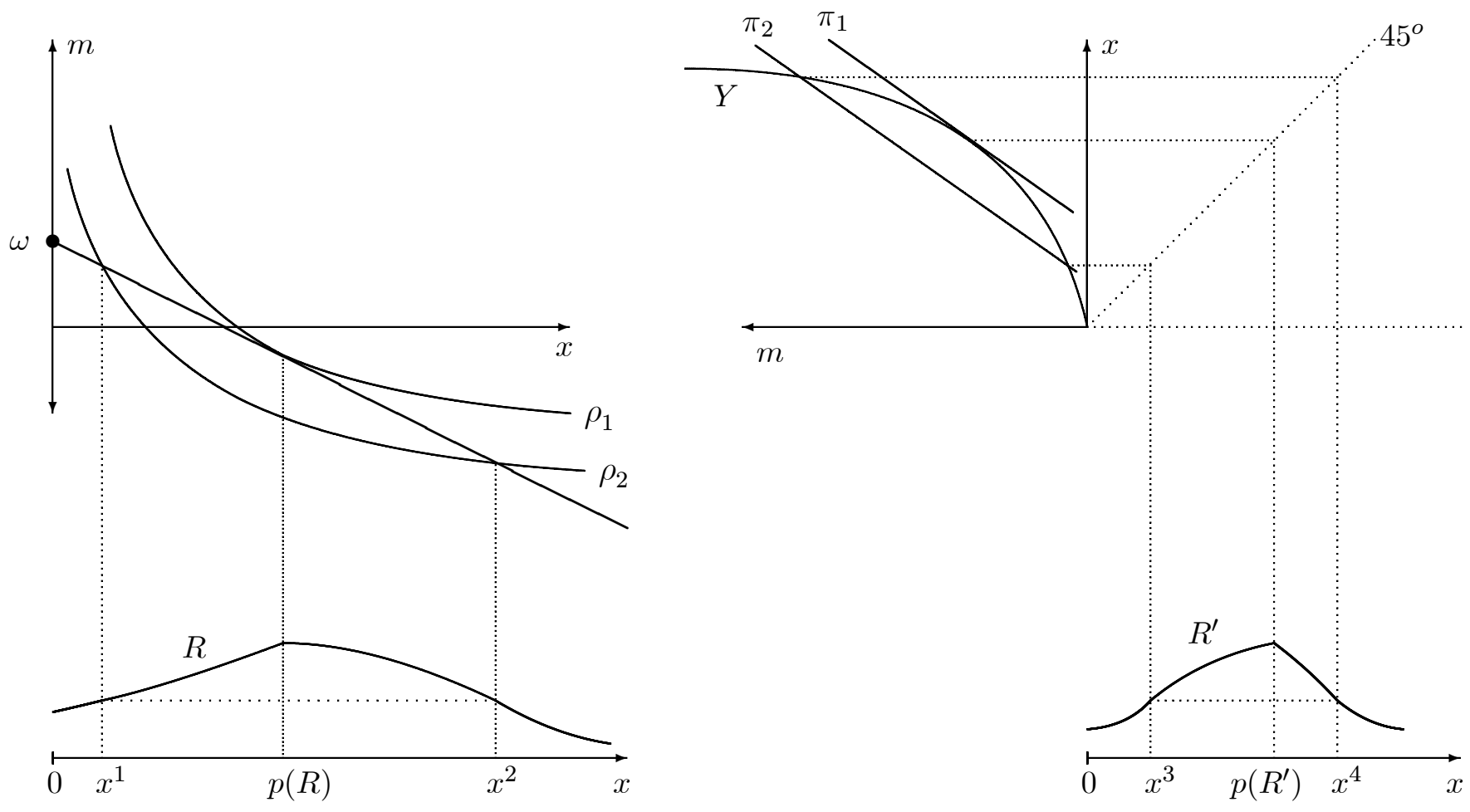

Figure 1: Constructing at the bottom the single-peaked preferences $R$ of a consumer (on the left) and $R^{\prime}$ of a producer (on the right) as a function of the parameters of the multiplegoods model presented at the top. According to $R$, the consumer is indifferent between $x^{1}$ and $x^{2}$ which are located at opposite sides of his peak $p(R)$. Similarly, the producer is indifferent between $x^{3}$ and $x^{4}$.

Figure 1 displays how information on a two-commodity model (comprised of a commodity $x$ and money $m$ ) is used to construct an agent's single peaked preferences on a commodity $x$. On the left, a consumer's preferences $\rho$, his endowment $\omega$, and the prices determine the consumer's single-peaked preferences $R$ on $x$. For simplicity, we assume that the consumer can borrow money to purchase any amount of $x .{ }^{5}$ On the right, a producer's production set $Y$ and the prices determine the producer's single-peaked preferences $R^{\prime}$ on $x$. Note that the consumer's preferences and the producer's profits are nonsatiated in Figure 1; the agents' peaks are due to the (consumption or production) constraints that they face.

A trade rule, in our model, takes in the preferences of the buyers and the sellers and in or input-consumption levels in terms of profits.

${ }^{5}$ Note that even when the agent borrows at an interest rate, the resulting preferences are single-peaked. Dropping the borrowing possibility introduces an additional parameter (a consumption constraint) to the single-peaked model. For such an extension of the Sprumont (1991) model, see Kıbris (2003). 
turn, delivers $(i)$ the volume of trade (i.e. the total trade that will be carried out between the buyers and the sellers) and ( $i i)$ how the volume of trade will be allocated among the agents on either side of the market. We introduce a class of Uniform trade rules each of which, in step $(i)$, determines the volume of trade as the median of total demand, total supply, and an exogenous constant and in step (ii), allocates this volume "uniformly" among agents on either side of the market.

There are earlier papers related to either one of the above steps but not both. The second (allocation) step is related to the literature starting with Sprumont (1991) who analyzes the problem of allocating a fixed social endowment of a private commodity among agents with single-peaked preferences. The social endowment in those problems corresponds in our model to the volume of trade which, in the second step is treated as fixed, and is allocated as total supply among the buyers and total demand among the sellers. On Sprumont's domain, an allocation rule called the Uniform Rule turns out to be central. It can be described as follows: if the sum of the agents' peaks is more (respectively, less) than the social endowment, each agent receives the minimum (respectively, the maximum) of his peak and a constant amount. The value of this constant is uniquely determined by the feasibility of the allocation. Sprumont (1991) shows that this rule uniquely satisfies (i) Pareto optimality, strategy proofness, and anonymity as well as (ii) Pareto optimality, strategy proofness, and no-envy. The Uniform rule satisfies many other desirable properties (e.g. see Ching (1992, 1994) and Thomson (1994 a, b)). Thus it is no surprise that in our model, the aforementioned Uniform trade rules employ the Uniform rule to allocate the trade volume among agents on either side of the market.

The first (trade-volume determination) step is intuitively (though not formally) related to Moulin (1980) who analyzes the determination of a one-dimensional policy issue among agents with single-peaked preferences. ${ }^{6}$ This relation is particularly apparent (and formal) when there is a single buyer and a single seller. Then the volume of trade is exactly like a public good for these two agents. While this is no more true when there are multiple buyers or seller (who are sharing the trade volume among themselves), the mechanics of determining the trade volume as a function of the total demand and total supply still resemble Moulin's (1980) model. This similarity becomes apparent in our results: parallel to the extended

\footnotetext{
${ }^{6}$ Consider, for example, the determination of a tax rate, the budget of a project, or the provision of a public good.
} 
median rules proposed there, strategic considerations lead us to propose the determination of the volume of trade as the median of total demand, total supply and an exogenous constant.

Let us however note that our model is richer than a simple conjunction of the two models mentioned above. This is particularly due to the interaction between the determination of the agents' shares and the determination of the trade volume. For example, the agents can manipulate their allotments also by manipulating (possibly as a group) the volume of trade. Also, single-economy requirements like Pareto optimality or "fairness" become much more demanding as what is to be allocated becomes endogenous. Another important difference is the existence of two types of agents (buyers and sellers) in our model. This duality limits the implications of requirements like anonymity or no-envy and, for example in comparison to Moulin (1980), allows for a much larger class of median rules some of which discriminates between the buyers and the sellers.

Our model is also related to those of Barberà and Jackson (1995), Thomson (1995), and Klaus, Peters, and Storcken (1997, 1998). Barberà and Jackson (1995) analyze a pure exchange economy with an arbitrary number of agents and commodities. Each agent has a positive endowment of the commodities and a continuous, strictly convex, and monotonic preference relation on his consumption. The authors look for strategy-proof rules to facilitate trade in this exchange economy. With this consideration, they introduce and characterize a class of "fixed-proportion trading rules" where $(i)$ trade can only occur in one proportion which is selected from an a priori fixed set of proportions satisfying certain restrictions due to which the set of feasible allocations is restricted to be a one-dimensional set on which the agents have single-peaked preferences and $(i i)$ given a proportion for trade, the final allocation is chosen by rationing the agents uniformly. Thomson (1995) and Klaus, Peters, and Storcken $(1997,1998)$ alternatively analyze a single-commodity model where they consider the reallocation of an infinitely divisible good among agents with single-peaked preferences and individual endowments. ${ }^{7}$ In their models, the agents whose endowments are greater than their peaks (the suppliers) supply to those whose endowments are less then their peaks (the demanders). They show that a set of basic properties characterize a "Uniform reallocation rule".

The relation between these models and ours is quite similar to the one between pure

\footnotetext{
${ }^{7}$ Thomson (1995) also allows an "open economy" extension where a transfer from the outside world (aside from the individual endowments) is to be allocated.
} 
exchange and production economies. In the pure exchange models, whether an agent is a supplier or a demander of the commodity in question depends on the relation between his preferences and his endowment. For example, by changing his preferences, a supplier can turn into a demander of the commodity in question and vice versa. In our production model, however, producers and consumers are exogenously distinct entities. This difference has significant implications on the analysis to be carried out. For example, fairness properties such as anonymity or no-envy compare all agents in the pure exchange version of the model whereas, in the production version, they can only compare agents on the same side of the market. ${ }^{8}$ Also, in our model, there are no exogenously set individual endowments. Only after the shares are determined, the production decisions are made. ${ }^{9}$ These differences reflect to the results obtained in the two models as well. In the pure exchange model, basic properties imply that the short side of the market always clears whereas this is not the case in our model. ${ }^{10}$ We thus interpret the exchange and production models (and their findings) as complements of each other in the aforementioned sense.

We look for trade rules that satisfy a set of standard properties such as Pareto optimality, (coalitional) strategy proofness, and no-envy. We also introduce a new property specific to this domain: separability in total trade requires the volume of trade only to depend on the total demand and supply but not on their individual components. For example, increasing agent $i$ 's demand and decreasing agent $j^{\prime} s$ demand so as to keep total demand unchanged should have no effect on the volume of trade. Note that this change can still effect the shares of these two agents as well as others.

We observe that the above properties are logically independent and in Theorem 1, we show that they are uniquely satisfied by a class of Uniform trade rules. As noted above, these rules do not necessarily clear the short side of the market. Such practice might seem unrealistic at first glance. However, real life examples to it are in fact more common than one

\footnotetext{
${ }^{8}$ Indeed, to consider envy between a producer and a consumer, one would need an environment where each consumer has access to a production technology and maybe even less realistically, each firm can turn itself into a consumer.

${ }^{9}$ Note that this is more than simply setting the endowments in Klaus et al $(1997,1998)$ to zero since in that case all agents in their model would become demanders of the commodity.

${ }^{10}$ The short side of a market is where the aggregate volume of desired transaction is smallest. It is thus the demand side if there is excess supply and the supply side if there is excess demand. The other side is called the long side.
} 
would initially expect, especially in markets with strong welfare implications for the society. In health or education sectors for example, it is not uncommon to observe excess demand due to price regulations and an overutilization of services (such as overfilled schools or hospitals). Similarly, there are many countries (such as that of the authors) where in response to an excess supply of labor, governments tend to over-employ in the public sector. Even in the private sector, since most labor contracts include restrictions on when and how the contract can be terminated, firms regularly experience periods in which they overemploy. Finally let us note that, especially when several interconnected markets are concerned, clearing the short side in every one of these markets might be problematic. Bénassy (1982, pages 11-12) presents the example of a firm that buys from an input market in excess demand and sells to an output market in excess demand. If the short side clears in the input market, the firm cannot produce at its profit maximizing level even though it faces excess demand. Thus in this example, application of the short side rule in the input market has efficiency implications on the output market.

We later analyze the implications of a stronger separability property. In Proposition 2, we show that any Pareto optimal and strategy proof trade rule that satisfies strong separability in total trade has to determine the volume of trade by an extended median rule that is constant across different societies. Adding no-envy (in allocations) and anonymity (in determination of the trade volume) restricts the admissible class of rules to Uniform trade rules $(i)$ that are constant across societies and $(i i)$ that do not discriminate between buyers and sellers.

We observe that among Uniform trade rules, renegotiation proof ones are those that clear exactly one side of the market in economies where there are less agents on the short side of the market than there is on the long side. Interestingly enough, renegotiation proofness has no implications for societies with an equal number of buyers and sellers.

We also observe that only the Uniform trade rule that clears the short side of the market satisfies a voluntary trade requirement that gives each agent the right to choose zero trade for himself (the term is introduced by Bénassy (1982), Chapter 6). For this, we show in Proposition 3 that any Pareto optimal and strategy proof trade rule that satisfies voluntary trade has to clear the short side of the market. Note that, in examples such as health services for infants or compulsory education for children, consumers (i.e. the parents) do not have the right to choose zero consumption. They are required by law to consume a 
minimum amount. ${ }^{11}$ Similarly, legal regulations define conditions under which health-care or education providers can not deny services. ${ }^{12}$ For such markets therefore, voluntary trade is not a desirable property. On the other hand, with the exception of certain epidemics, adults have voluntary trade power in determining their consumption of health services.

The paper is organized as follows. In Section 2, we introduce the model and in Section 3, we introduce and discuss Uniform trade rules. Section 4 contains the main results. We conclude in Section 5 .

\section{The Model}

There is a (countable) universal set $\mathcal{B}$ of potential buyers and a (countable) universal set $\mathcal{S}$ of potential sellers. Let $\mathcal{B} \cap \mathcal{S}=\emptyset$. There is a perfectly divisible commodity that each seller produces and each buyer consumes. Let $\mathbb{R}_{+}$be the consumption/production space for each agent. Each $i \in \mathcal{B} \cup \mathcal{S}$ is endowed with a continuous preference relation $R_{i}$ over $\mathbb{R}_{+}$. Let $P_{i}$ denote the strict preference relation associated with $R_{i}$. The preference relation $R_{i}$ is single-peaked if there is $p\left(R_{i}\right) \in \mathbb{R}_{+}$, called the peak of $R_{i}$, such that for all $x_{i}, y_{i}$ in $\mathbb{R}_{+}$, $x_{i}<y_{i} \leq p\left(R_{i}\right)$ or $x_{i}>y_{i} \geq p\left(R_{i}\right)$ implies $y_{i} P_{i} x_{i}$. Let $\mathcal{R}$ denote the set of all continuous and single-peaked preference relations on $\mathbb{R}_{+}$.

Given a finite set $B \subset \mathcal{B}$ of buyers and a finite set $S \subset \mathcal{S}$ of sellers, let $N=B \cup S$ be a society. Let $\mathcal{N}=\{B \cup S \mid B \subset \mathcal{B}$ and $S \subset \mathcal{S}$ are finite sets $\}$ be the set of all societies. A preference profile $R_{N}$ for a society $N$ is a list $\left(R_{i}\right)_{i \in N}$ such that for each $i \in N, R_{i} \in \mathcal{R}$. Let $\mathcal{R}^{N}$ denote the set of all profiles for the society $N$. Given $R_{N} \in \mathcal{R}^{N}$, let $p\left(R_{N}\right)=\left(p\left(R_{i}\right)\right)_{i \in N}$. Given $N^{\prime} \subset N$ and $R_{N} \in \mathcal{R}^{N}$, let $R_{N^{\prime}}=\left(R_{i}\right)_{i \in N^{\prime}}$ denote the restriction of $R_{N}$ to $N^{\prime}$. A market for society $B \cup S$ is a profile of preferences for buyers and seller $\left(R_{B}, R_{S}\right) \in \mathcal{R}^{B \cup S}$. Let

$$
\mathcal{M}=\bigcup_{(B \cup S) \in \mathcal{N}} \mathcal{R}^{B \cup S}
$$

\footnotetext{
${ }^{11}$ As another example, consider countries where the laws require purchase of a minimum insurance coverage at a fixed price (such as health insurance for employees or car insurance for drivers).

${ }^{12}$ For example, the Coalition for Adequate School Housing reports that more than one million California school children attend an overcrowded school. In 47 school districts across California, student population densities are in excess of $200 \%$ of California Department of Education guidelines. For more, see http : //www.capta.org/sections/advocacy/alert - 012704.cfm
} 
be the set of all markets.

A (feasible) trade for $\left(R_{B}, R_{S}\right) \in \mathcal{M}$ is a vector $z \in \mathbb{R}_{+}^{B \cup S}$ such that $\sum_{B} z_{i}=\sum_{S} z_{i}$. For each buyer (seller) $i, z_{i}$ denotes how much he buys (sells). Let $Z(B \cup S)$ denote the set of all trades for $\left(R_{B}, R_{S}\right)$. A trade $z \in Z(B \cup S)$ is Pareto optimal with respect to $\left(R_{B}, R_{S}\right)$ if there is no $z^{\prime} \in Z(B \cup S)$ such that for all $i \in B \cup S, z_{i}^{\prime} R_{i} z_{i}$ and for some $j \in B \cup S, z_{i}^{\prime} P_{i} z_{i}$. In our framework, Pareto optimal trades possess the following property.

Lemma 1 For each $\left(R_{B}, R_{S}\right) \in \mathcal{M}$, the trade $z \in Z(B \cup S)$ is Pareto optimal with respect to $\left(R_{B}, R_{S}\right)$ if and only if for $K \in\{B, S\}, \sum_{K} p\left(R_{k}\right) \leq \sum_{N \backslash K} p\left(R_{k}\right)$ implies $(i) p\left(R_{k}\right) \leq z_{k}$ for each $k \in K,($ ii $) z_{j} \leq p\left(R_{j}\right)$ for each $j \in N \backslash K$, and thus $(i i i) \sum_{K} p\left(R_{k}\right) \leq \sum_{K} z_{k} \leq$ $\sum_{N \backslash K} p\left(R_{k}\right)$.

Proof. Let $\left(R_{B}, R_{S}\right) \in \mathcal{M}$ be such that $\sum_{K} p\left(R_{k}\right) \leq \sum_{N \backslash K} p\left(R_{k}\right)$.

Assume that $z \in Z(B \cup S)$ is Pareto optimal. First note that if there is $i \in K$ such that $z_{i}<p\left(R_{i}\right)$ and there is $j \in N \backslash K$ such that $z_{j}<p\left(R_{j}\right)$, then there is $\varepsilon>0$ such that $z^{\prime} \in Z(B \cup S)$ defined as for all $k \notin\{i, j\}, z_{k}^{\prime}=z_{k}, z_{i}^{\prime}=z_{i}+\varepsilon$, and $z_{j}^{\prime}=z_{j}+\varepsilon$ Pareto dominates $z$. Similarly, if there is $i \in K$ such that $z_{i}>p\left(R_{i}\right)$ and there is $j \in N \backslash K$ such that $z_{j}>p\left(R_{j}\right)$, we obtain a similar contradiction.

Now note that if $\sum_{K} z_{k}<\sum_{K} p\left(R_{k}\right) \leq \sum_{N \backslash K} p\left(R_{k}\right)$, then there is $i \in K$ such that $z_{i}<p\left(R_{i}\right)$ and there is $j \in N \backslash K$ such that $z_{j}<p\left(R_{j}\right)$. Similarly, if $\sum_{K} p\left(R_{k}\right) \leq$ $\sum_{N \backslash K} p\left(R_{k}\right)<\sum_{K} z_{k}$, then there is $i \in K$ such that $z_{i}>p\left(R_{i}\right)$ and there is $j \in N \backslash K$ such that $z_{j}>p\left(R_{j}\right)$. Thus $\sum_{K} p\left(R_{k}\right) \leq \sum_{K} z_{k} \leq \sum_{N \backslash K} p\left(R_{k}\right)$.

Finally, if there is $i, j \in K$ such that $z_{i}<p\left(R_{i}\right)$ and $z_{j}>p\left(R_{j}\right)$, there is $\varepsilon>0$ such that $z_{i}^{\prime}=z_{i}+\varepsilon, z_{j}^{\prime}=z_{j}-\varepsilon$, and for all $k \in K \backslash\{i, j\}, z_{k}^{\prime}=z_{k}$ is a Pareto improvement over $z$. This and $\sum_{K} p\left(R_{k}\right) \leq \sum_{K} z_{k}$ implies that for each $i, j \in K, z_{i} \geq p\left(R_{i}\right)$ and $z_{j} \geq p\left(R_{j}\right)$. A similar argument proves that for each $i, j \in N \backslash K, z_{i} \leq p\left(R_{i}\right)$ and $z_{j} \leq p\left(R_{j}\right)$.

For the converse, assume $p\left(R_{k}\right) \leq z_{k}$ for each $k \in K$ and $z_{l} \leq p\left(R_{l}\right)$ for each $l \in N \backslash K$. Let $z^{\prime} \in Z(B \cup S)$ be such that for some $i \in K, z_{i}^{\prime} P_{i} z_{i}$. Then $z_{i}^{\prime}<z_{i}$. This implies that either there is $j \in K$ such that $z_{j}^{\prime}>z_{j} \geq p\left(R_{j}\right)$ or there is $l \in N \backslash K$ such that $z_{l}^{\prime}<z_{l} \leq p\left(R_{l}\right)$. Thus $z^{\prime}$ does not Pareto dominate $z$. A similar argument follows if there is $i \in N \backslash K$ such that $z_{i}^{\prime} P_{i} z_{i}$. Thus $z$ is Pareto optimal.

A trade rule $F: \mathcal{M} \rightarrow \bigcup_{N \in \mathcal{N}} Z(N)$ associates each market $\left(R_{B}, R_{S}\right)$ with a trade $z \in Z(B \cup S)$. Let $\Omega_{F}(\cdot)=\sum_{i \in B} F_{i}(\cdot)$ be the associated rule that determines the volume 
of trade. In what follows, we introduce properties that are related to the four main titles in axiomatic analysis: efficiency, nonmanipulability, fairness, and stability.

We start with efficiency. A trade rule $F$ is Pareto optimal if for each $\left(R_{B}, R_{S}\right) \in \mathcal{M}$, the trade $F\left(R_{B}, R_{S}\right)$ is Pareto optimal with respect to $\left(R_{B}, R_{S}\right)$.

We present two properties on nonmanipulability. A trade rule $F$ is strategy proof if for each $N \in \mathcal{N}, R_{N} \in \mathcal{R}^{N}, i \in N$, and $R_{i}^{\prime} \in \mathcal{R}, F_{i}\left(R_{i}, R_{N \backslash i}\right) R_{i} F_{i}\left(R_{i}^{\prime}, R_{N \backslash i}\right)$. That is, regardless of the others' preferences, an agent is best-off with the trade associated with her true preferences. Strategy proof rules do not give the agents incentive for individual manipulation. They however are not immune to manipulation by groups. For this, a stronger property is necessary: a trade rule $F$ is coalitional strategy proof if for each $N \in \mathcal{N}, R_{N} \in$ $\mathcal{R}^{N}, M \subset N$, and $R_{M}^{\prime} \in \mathcal{R}^{M}$, if there is $i \in M$ such that $F_{i}\left(R_{M}^{\prime}, R_{N \backslash M}\right) P_{i} F_{i}\left(R_{M}, R_{N \backslash M}\right)$ then, there is $j \in M$ such that $F_{j}\left(R_{M}, R_{N \backslash M}\right) P_{j} F_{j}\left(R_{M}^{\prime}, R_{N \backslash M}\right) .{ }^{13}$

Our first fairness property is after Foley (1967). Since in our model the agents on different sides of the market are exogenously differentiated, our version of the property only compares agents on the same side of the market. A trade rule $F$ is envy free (equivalently, satisfies no-envy) if for each $\left(R_{B}, R_{S}\right) \in \mathcal{M}, K \in\{B, S\}$, and $i, j \in K, F_{i}\left(R_{B}, R_{S}\right) R_{i} F_{j}\left(R_{B}, R_{S}\right)$. In an envy free trade, each buyer (respectively, seller) prefers his own consumption (respectively, production) to that of every other buyer (respectively, seller).

No-envy restricts the set of allocations a trade rule $F$ can choose for each volume of trade. It however does not restrict the set of trade volumes that $F$ can choose (since, for every positive volume of trade, there are envy free allocations as well as allocations that create envy). The following anonymity properties, on the other hand, regulate the way the trade volume is chosen.

A bijection $\pi: \mathcal{B} \cup \mathcal{S} \rightarrow \mathcal{B} \cup \mathcal{S}$ which satisfies $\pi(i) \in \mathcal{B}(\pi(i) \in \mathcal{S})$ if and only if $i \in \mathcal{B}$ $(i \in \mathcal{S})$ is called an in-group-permutation. Let $\Pi$ be the set of all in-group-permutations and let $R_{\pi(i)}^{\pi}=R_{i}$ for each $\pi \in \Pi$ and $i \in \mathcal{B} \cup \mathcal{S}$. A trade rule $F$ satisfies in-group anonymity in total trade if for each $\left(R_{B}, R_{S}\right) \in \mathcal{M}$ and each $\pi \in \Pi, \Omega_{F}\left(R_{B}, R_{S}\right)=\Omega_{F}\left(R_{\pi(B)}^{\pi}, R_{\pi(S)}^{\pi}\right)$. This is a standard anonymity property which says that any two buyers (or, any two sellers) are similar in terms of how they affect the trade volume. That is, permuting their preferences has no effect on the trade volume, though it might affect the agents' shares. Note that the

\footnotetext{
${ }^{13}$ Note that ours is the stronger formulation of the property. A weaker version considers only coalitional manipulations that make all agents in the coalition strictly better-off.
} 
property does not compare a buyer to a seller.

A bijection $\phi: \mathcal{B} \cup \mathcal{S} \rightarrow \mathcal{B} \cup \mathcal{S}$ which satisfies $\phi(i) \in \mathcal{B}(\phi(i) \in \mathcal{S})$ if and only if $i \in \mathcal{S}$ $(i \in \mathcal{B})$ is called a between-group-permutation. ${ }^{14}$ Let $\Phi$ be the set of all between-grouppermutations and let $R_{\phi(i)}^{\phi}=R_{i}$ for each $\phi \in \Phi$ and $i \in \mathcal{B} \cup \mathcal{S}$. A trade rule $F$ satisfies between-group anonymity in total trade if for each $\left(R_{B}, R_{S}\right) \in \mathcal{M}$ and each $\phi \in \Phi$, $\Omega_{F}\left(R_{B}, R_{S}\right)=\Omega_{F}\left(R_{\phi(S)}^{\phi}, R_{\phi(B)}^{\phi}\right)$. Unlike in-group anonymity, this property compares two sides of the market in terms of how they affect the trade volume. It requires that permuting the supply and the demand data (that is, calling supply what used to be called demand and vice versa) has no effect on the trade volume. In this sense, a between-group anonymous rule satisfies a certain symmetry in terms how it treats the two sides of the market (for more on this point, please see Corollary 1 and Remark 2). ${ }^{15}$ For example, a trade rule that always picks the trade volume to be equal to the aggregate demand violates this property (even though it satisfies in-group anonymity in total trade).

It turns out that the two anonymity properties are logically related. This is because any in-group permutation can be written as a composition of two between-group permutations.

Lemma 2 Let $|\mathcal{B}|=|\mathcal{S}|$. If a trade rule $F$ satisfies between-group anonymity in total trade, it also satisfies in-group anonymity in total trade.

Proof. Let $F$ satisfy between-group anonymity in total trade. Let $\left(R_{B}, R_{S}\right) \in \mathcal{M}$ and $\pi \in \Pi$. We want to show $\Omega_{F}\left(R_{B}, R_{S}\right)=\Omega_{F}\left(R_{\pi(B)}^{\pi}, R_{\pi(S)}^{\pi}\right)$.

Since $\mathcal{B}$ and $\mathcal{S}$ are countable sets, enumerate $\mathcal{B}=\left\{b_{i}\right\}_{i=1}^{|\mathcal{B}|}$ and $\mathcal{S}=\left\{s_{i}\right\}_{i=1}^{|\mathcal{S}|}$. Then, define $\phi: \mathcal{B} \cup \mathcal{S} \rightarrow \mathcal{B} \cup \mathcal{S}$ as $\phi\left(b_{i}\right)=s_{i}$ and $\phi\left(s_{i}\right)=b_{i}$ for all $i \in\{1, \ldots,|\mathcal{B}|\}$. Finally, define $\phi^{\prime}: \mathcal{B} \cup \mathcal{S} \rightarrow \mathcal{B} \cup \mathcal{S}$ as $\phi^{\prime}\left(b_{i}\right)=\pi\left(s_{i}\right)$ and $\phi^{\prime}\left(s_{i}\right)=\pi\left(b_{i}\right)$. Since $|\mathcal{B}|=|\mathcal{S}|, \phi, \phi^{\prime} \in \Phi$ are well-defined between-group permutations.

Now $\phi^{\prime}\left(\phi\left(b_{i}\right)\right)=\phi^{\prime}\left(s_{i}\right)=\pi\left(b_{i}\right)$ and $\phi^{\prime}\left(\phi\left(s_{i}\right)\right)=\phi^{\prime}\left(b_{i}\right)=\pi\left(s_{i}\right)$ imply $\pi=\phi^{\prime} \circ \phi$. Thus $\Omega_{F}\left(R_{\pi(B)}^{\pi}, R_{\pi(S)}^{\pi}\right)=\Omega_{F}\left(R_{\phi^{\prime}(\phi(B))}^{\phi^{\prime} \circ \phi}, R_{\phi^{\prime}(\phi(S))}^{\phi^{\prime} \phi}\right)$. Finally, applying between-group anonymity in total trade twice gives $\Omega_{F}\left(R_{\phi^{\prime}(\phi(B))}^{\phi^{\prime} \circ}, R_{\phi^{\prime}(\phi(S))}^{\phi^{\prime} \phi}\right)=\Omega_{F}\left(R_{\phi(S)}^{\phi}, R_{\phi(B)}^{\phi}\right)=\Omega_{F}\left(R_{B}, R_{S}\right)$, the desired conclusion.

\footnotetext{
${ }^{14}$ For $\phi$ to be well-defined, one needs $|\mathcal{B}|=|\mathcal{S}|$. Since this assumption is not used elsewhere, it will be exclusively stated in results that use between-group-permutations.

${ }^{15}$ Note that desirability of every property depends on the specifics of the problem on which it is being used. In our opinion, between-group anonymity is particularly desirable if both sides of the market are comprised of firms. Then it requires symmetric treatment of two sectors.
} 
Our fourth title is stability. We introduce two properties related to it. The first property is for markets where a buyer-seller pair can renegotiate a deal among themselves. A trade rule $F$ is renegotiation proof if for each $\left(R_{B}, R_{S}\right) \in \mathcal{M}$ there is no $i \in S$ and $j \in B$ such that for some $r \in \mathbb{R}_{+}, r P_{i} F_{i}\left(R_{B}, R_{S}\right)$ and $r P_{j} F_{j}\left(R_{B}, R_{S}\right)$. This is a weak no-blocking property. ${ }^{16}$ Our final stability property is for markets where each agent is entitled to leaving the market, that is, buying or selling zero units. A trade rule $F$ satisfies voluntary trade if for each $\left(R_{B}, R_{S}\right) \in \mathcal{M}$ and $i \in B \cup S, F_{i}\left(R_{B}, R_{S}\right) R_{i} 0$.

Lastly, we introduce the following informational simplicity property. It requires the volume of trade only to depend on the total demand and supply but not on their individual components. A trade rule $F$ satisfies separability (in total trade) if for each $(B \cup S) \in \mathcal{N}$ and $\left(R_{B}, R_{S}\right),\left(R_{B}^{\prime}, R_{S}^{\prime}\right) \in \mathcal{R}^{B \cup S}, \sum_{i \in B} p\left(R_{i}\right)=\sum_{i \in B} p\left(R_{i}^{\prime}\right)$ and $\sum_{i \in S} p\left(R_{i}\right)=\sum_{i \in S} p\left(R_{i}^{\prime}\right)$ implies $\Omega_{F}\left(R_{B}, R_{S}\right)=\Omega_{F}\left(R_{B}^{\prime}, R_{S}^{\prime}\right)$. Note that this property is not logically related to either anonymity in total trade property since it does not make the determination of trade volume independent of the agents' identities. It merely relates two problems with the same set of agents. A stronger separability property would totally disregard the agents' identities: a trade rule $F$ satisfies strong separability (in total trade) if for each $(B \cup S),\left(B^{\prime} \cup S^{\prime}\right) \in \mathcal{N}$, $\left(R_{B}, R_{S}\right) \in \mathcal{R}^{B \cup S}$, and $\left(R_{B^{\prime}}^{\prime}, R_{S^{\prime}}^{\prime}\right) \in \mathcal{R}^{B^{\prime} \cup S^{\prime}}, \sum_{i \in B} p\left(R_{i}\right)=\sum_{i \in B^{\prime}} p\left(R_{i}^{\prime}\right)$ and $\sum_{i \in S} p\left(R_{i}\right)=$ $\sum_{i \in S^{\prime}} p\left(R_{i}^{\prime}\right)$ implies $\Omega_{F}\left(R_{B}, R_{S}\right)=\Omega_{F}\left(R_{B^{\prime}}^{\prime}, R_{S^{\prime}}^{\prime}\right)$. Note that since the sets $B$ and $B^{\prime}$ (as well as $S$ and $S^{\prime}$ ) are allowed to be of different cardinality, this property is stronger than a conjunction of separability and in-group anonymity in total trade.

It follows from Lemma 1 that verifying Pareto optimality only requires information about the agents' peaks. This is also true for both separability and strong separability. Verification of all the other properties requires full preference information. Verifying (coalitional) strategy proofness, no envy, renegotiation proofness, and voluntary trade requires knowledge of how an agent compares two bundles at opposite sides of his peak. The anonymity properties require verification of whether a profile is a permutation of another and thus also require full preference information.

We next introduce the class of Uniform trade rules and analyze the properties they all satisfy.

\footnotetext{
${ }^{16}$ We will later note that requiring a stronger version of the property that allows any coalition to form does not affect our results. Allowing some agents in a blocking-coalition to remain indifferent, on the other hand, has strong implications.
} 


\section{Uniform Trade Rules}

Let $\beta: \mathcal{N} \rightarrow \mathbb{R}_{+} \cup\{\infty\}$ and $\sigma: \mathcal{N} \rightarrow \mathbb{R}_{+} \cup\{\infty\}$ be two functions such that for each $B \cup S \in \mathcal{N}, B=\emptyset$ or $S=\emptyset$ implies $\beta(B \cup S)=\sigma(B \cup S)=0$. The Uniform trade rule with respect to $\boldsymbol{\beta}$ and $\boldsymbol{\sigma}, \mathbf{U T}^{\boldsymbol{\beta} \sigma}$, is then defined as follows. We first determine the volume of trade: given $(B \cup S) \in \mathcal{N}$ and $\left(R_{B}, R_{S}\right) \in \mathcal{R}^{B \cup S}$, let

$\Omega_{U T^{\beta \sigma}}\left(R_{B}, R_{S}\right)=\left\{\begin{array}{lll}\operatorname{median}\left\{\beta(B \cup S), \sum_{B} p\left(R_{i}\right), \sum_{S} p\left(R_{i}\right)\right\} & \text { if } \quad & \left.\sum_{B} p\left(R_{i}\right) \leq \sum_{S} p\left(R_{i}\right)\right\}, \\ \operatorname{median}\left\{\sigma(B \cup S), \sum_{B} p\left(R_{i}\right), \sum_{S} p\left(R_{i}\right)\right\} & \left.\text { if } \quad \sum_{B} p\left(R_{i}\right) \geq \sum_{S} p\left(R_{i}\right)\right\} .\end{array}\right.$

That is, a median rule with the exogenous reference-point $\beta(B \cup S)$ is used when the buyers are the short side of the market. If, on the other hand, the sellers are the short side, then the reference point $\sigma(B \cup S)$ is used to calculate the median.

Next, we allocate the volume of trade among the agents: for $K \in\{B, S\}$, let

$$
U T_{K}^{\beta \sigma}\left(R_{B}, R_{S}\right)=\left\{\begin{array}{llc}
\left(\min \left\{\lambda, p\left(R_{i}\right)\right\}\right)_{i \in K} & \text { if } \quad & \sum_{K} p\left(R_{i}\right) \geq \Omega_{U T^{\beta \sigma}}\left(R_{B}, R_{S}\right), \\
\left(\max \left\{\lambda, p\left(R_{i}\right)\right\}\right)_{i \in K} & \text { if } \quad & \sum_{K} p\left(R_{i}\right) \leq \Omega_{U T^{\beta \sigma}}\left(R_{B}, R_{S}\right) .
\end{array}\right.
$$

where $\lambda \in \mathbb{R}_{+}$satisfies

$$
\sum_{K} \min \left\{\lambda, p\left(R_{i}\right)\right\}=\Omega_{U T^{\beta \sigma}}\left(R_{B}, R_{S}\right) \quad \text { if } \quad \sum_{K} p\left(R_{i}\right) \geq \Omega_{U T^{\beta \sigma}}\left(R_{B}, R_{S}\right)
$$

and

$$
\sum_{K} \max \left\{\lambda, p\left(R_{i}\right)\right\}=\Omega_{U T^{\beta \sigma}}\left(R_{B}, R_{S}\right) \quad \text { if } \quad \sum_{K} p\left(R_{i}\right)<\Omega_{U T^{\beta \sigma}}\left(R_{B}, R_{S}\right) .
$$

The class of Uniform trade rules is very rich. It contains rules that for example always favor the buyers $(\beta=0$ and $\sigma=\infty)$, rules that always favor the short side of the market $(\beta=\sigma=0)$, or rules that guarantee a fixed volume of trade unless both sides of the market wish to deviate from it $\left(\beta=\sigma=c \in \mathbb{R}_{+}\right)$, as well as rules that mix between these and many other arbitration methods based on the identities of the agents and who constitutes the short side of the market.

We interpret the $\beta$ and the $\sigma$ functions as institutional parameters that are determined by the state through a political process and enforced via the legal system. For positive 
values of these parameters, there are markets in which some buyers (sellers) are required by law to buy (sell) more than their peak. As an example, consider countries with conscription requirements: each male (in some countries, also female) citizen of a certain age is required to supply a minimum amount of labor time (which can go up to two years) in the armed forces (some countries allow civil service as well). Since the pay during this service is typically below the market wage rate, there is excess demand in such labor markets. The amount of trade in a given period is a determinant of the size of a country's army which, in turn, is an important policy choice that is determined politically and not changed frequently. In a static model, it can be interpreted as a $\sigma$ parameter for this labor market.

The following proposition analyzes the common properties that all Uniform trade rules satisfy.

Proposition 1 All Uniform trade rules satisfy Pareto optimality, coalitional strategy proofness, no-envy, and separability in total trade.

Proof. Separability in total trade follows from the median definition of $\Omega_{U^{\beta \sigma}}$. To show that $U T^{\beta \sigma}$ satisfies Pareto optimality, note that by the median definition of $\Omega_{U T^{\beta \sigma}}$, we have

$$
\sum_{K} p\left(R_{i}\right) \leq \Omega_{U T^{\beta \sigma}}\left(R_{B}, R_{S}\right) \leq \sum_{N \backslash K} p\left(R_{i}\right)
$$

for $K \in\{B, S\}$. Thus there is $\rho, \lambda \in \mathbb{R}_{+}$such that

$$
\sum_{K} \max \left\{\rho, p\left(R_{i}\right)\right\}=\Omega_{U T^{\beta \sigma}}\left(R_{B}, R_{S}\right)=\sum_{N \backslash K} \min \left\{\lambda, p\left(R_{i}\right)\right\} .
$$

Thus for each $i \in K, U T_{i}^{\beta \sigma}\left(R_{B}, R_{S}\right) \geq p\left(R_{i}\right)$ and for each $i \in N \backslash K, U T_{i}^{\beta \sigma}\left(R_{B}, R_{S}\right) \leq p\left(R_{i}\right)$. This, by Lemma 1, implies the desired conclusion.

To show that $U T^{\beta \sigma}$ satisfies no envy, let $R_{B \cup S} \in \mathcal{M}$ and $i \in K \in\{B, S\}$. No envy trivially holds if $U T_{i}^{\beta \sigma}\left(R_{N}\right)=p\left(R_{i}\right)$. Alternatively $U T_{i}^{\beta \sigma}\left(R_{N}\right)<p\left(R_{i}\right)$ implies $U T_{j}^{\beta \sigma}\left(R_{N}\right) \leq$ $U T_{i}^{\beta \sigma}\left(R_{N}\right)$ for each $j \in K$. Similarly $U T_{i}^{\beta \sigma}\left(R_{N}\right)>p\left(R_{i}\right)$ implies $U T_{j}^{\beta \sigma}\left(R_{N}\right) \geq U T_{i}^{\beta \sigma}\left(R_{N}\right)$ for each $j \in K$. Therefore, $U T_{i}^{\beta \sigma}\left(R_{N}\right) R_{i} U T_{j}^{\beta \sigma}\left(R_{N}\right)$ for each $j \in K$.

To show that $U T^{\beta \sigma}$ satisfies coalitional strategy proofness, take an arbitrary market $R_{N}=\left(R_{B}, R_{S}\right) \in \mathcal{M}$. Let $z=U T^{\beta \sigma}\left(R_{N}\right), \omega=\Omega_{U T^{\beta \sigma}}\left(R_{N}\right), M \subset N$, and $R_{M}^{\prime} \in \mathcal{R}^{M}$. Let $R_{N}^{\prime}=\left(R_{M}^{\prime}, R_{N \backslash M}\right), z^{\prime}=U T^{\beta \sigma}\left(R_{N}^{\prime}\right)$ and $\omega^{\prime}=\Omega_{U T^{\beta \sigma}}\left(R_{N}^{\prime}\right)$. Suppose there is $i \in M$ such that $z_{i}^{\prime} P_{i} z_{i}$. This implies $z_{i} \neq p\left(R_{i}\right)$. Without loss of generality, let $i \in S$. Then, $\sum_{S} p\left(R_{k}\right) \neq \omega$. 
Without loss of generality, let $\sum_{S} p\left(R_{k}\right)>\omega$. Then, by the definition of $U T^{\beta \sigma}$, there is $\lambda \in \mathbb{R}_{+}$such that $z_{i}=\lambda=\min \left\{\lambda, p\left(R_{i}\right)\right\}<z_{i}^{\prime}$.

Case 1: $\omega^{\prime} \leq \omega$ and $\sum_{S} p\left(R_{k}^{\prime}\right) \geq \omega^{\prime}$

By the definition of $U T^{\beta \sigma}$, there is $\lambda^{\prime} \in \mathbb{R}_{+}$such that $z_{i}^{\prime}=\min \left\{\lambda^{\prime}, p\left(R_{i}^{\prime}\right)\right\} \leq \lambda^{\prime}$. This implies $\lambda^{\prime}>\lambda$. Since

$$
\sum_{S} z_{k}^{\prime}=\omega^{\prime} \leq \omega=\sum_{S} z_{k}
$$

there is $j \in S$ such that $z_{j}^{\prime}<z_{j}$ which implies $z_{j} P_{j} z_{j}^{\prime}$. Moreover, $j \in M$. To see this suppose $j \notin M$. Then, $R_{j}^{\prime}=R_{j}$. This implies $z_{j}^{\prime}=\min \left\{\lambda^{\prime}, p\left(R_{j}\right)\right\} \geq \min \left\{\lambda, p\left(R_{j}\right)\right\}=z_{j}$, a contradiction.

Case 2: $\omega^{\prime} \leq \omega$ and $\sum_{S} p\left(R_{k}^{\prime}\right)<\omega^{\prime}$

Then there is $\theta \in \mathbb{R}_{+}$such that $z_{i}^{\prime}=\max \left\{\theta, p\left(R_{i}^{\prime}\right)\right\}>z_{i}=\min \left\{\lambda, p\left(R_{i}\right)\right\}$. Since $\omega^{\prime} \leq \omega$, there is $j \in S$ such that $z_{j}^{\prime}<z_{j}$ which implies $z_{j} P_{j} z_{j}^{\prime}$. We claim that $j \in M$. To see this suppose $j \notin M$. Then, $z_{j}^{\prime}=\max \left\{\theta, p\left(R_{j}\right)\right\} \geq p\left(R_{j}\right)$ and $z_{j}=\min \left\{\lambda, p\left(R_{j}\right)\right\} \leq p\left(R_{j}\right)$. This implies $z_{j}^{\prime} \geq z_{j}$, a contradiction.

Case 3: $\omega^{\prime}>\omega$

Then, $\sum_{B} p\left(R_{k}^{\prime}\right) \geq \omega^{\prime}$. To see this, suppose $\sum_{B} p\left(R_{k}^{\prime}\right)<\omega^{\prime}$. But $\beta(B \cup S) \leq \omega<\omega^{\prime}$ then contradicts

$$
\omega^{\prime}=\operatorname{median}\left\{\beta(B \cup S), \sum_{B} p\left(R_{k}^{\prime}\right), \sum_{S} p\left(R_{k}^{\prime}\right)\right\} .
$$

By the definition of $U T^{\beta \sigma}$, there are $\rho, \rho^{\prime} \in \mathbb{R}_{+}$such that $z_{k}=\max \left\{\rho, p\left(R_{k}\right)\right\}$ and $z_{k}^{\prime}=\min \left\{\rho^{\prime}, p\left(R_{k}^{\prime}\right)\right\}$ for each $k \in B$. Since $\omega=\sum_{B} z_{k}<\omega^{\prime}=\sum_{B} z_{k}^{\prime}$, there is $j \in B$ such that $z_{j}<z_{j}^{\prime}$. Then $p\left(R_{j}\right) \leq z_{j}<z_{j}^{\prime}$ which implies $z_{j} P_{j} z_{j}^{\prime}$. We claim that $j \in M$. Suppose this is not the case. Then $R_{j}=R_{j}^{\prime}$. So, $z_{j}=\max \left\{\rho, p\left(R_{j}\right)\right\}<z_{j}^{\prime}=\min \left\{\rho^{\prime}, p\left(R_{j}\right)\right\}$, a contradiction.

All Uniform trade rules satisfy a core-like property which requires that no coalition of agents can make all its members better-off by reallocating the shares (assigned by a trade rule) of its members among themselves. On the other hand, properties such as anonymity in total trade, strong separability, renegotiation proofness, and voluntary trade are not satisfied by all Uniform trade rules. In the next section, this is discussed in further detail. 


\section{Results}

We first present two lemmas that are extensions of standard results by Ching (1994) to our domain. ${ }^{17}$ They both are about the regularities that a Pareto optimal and strategy proof rule exhibits. The first result can be called a "monotonicity lemma" since it states that an increase (decrease) in an agent's peak moves his share in the same direction.

Lemma 3 Let the trade rule $F$ satisfy Pareto optimality and strategy proofness. Then for each $N \in \mathcal{N}, i \in N$, and $\left(R_{i}, R_{-i}\right),\left(R_{i}^{\prime}, R_{-i}\right) \in \mathcal{R}^{N}$, if $p\left(R_{i}\right) \leq p\left(R_{i}^{\prime}\right)$, then $F_{i}\left(R_{i}, R_{-i}\right) \leq$ $F_{i}\left(R_{i}^{\prime}, R_{-i}\right)$.

Proof. Suppose $F_{i}\left(R_{i}^{\prime}, R_{-i}\right)<F_{i}\left(R_{i}, R_{-i}\right)$. Then there are three possible cases. If

$$
F_{i}\left(R_{i}^{\prime}, R_{-i}\right)<F_{i}\left(R_{i}, R_{-i}\right) \leq p\left(R_{i}\right) \leq p\left(R_{i}^{\prime}\right)
$$

then with preferences $R_{i}^{\prime}$, agent $i$ has an incentive to declare $R_{i}$. If $p\left(R_{i}\right) \leq p\left(R_{i}^{\prime}\right) \leq$ $F_{i}\left(R_{i}, R_{-i}\right)$, then let $K \in\{B, S\}$ be such that $i \in K$ and note that $p\left(R_{i}^{\prime}\right)+\sum_{K \backslash\{i\}} p\left(R_{k}\right) \leq$ $\Omega_{F}\left(R_{N \backslash K}, R_{K}\right) \leq \sum_{N \backslash K} p\left(R_{k}\right)$. Thus by Pareto optimality, $p\left(R_{i}^{\prime}\right) \leq F_{i}\left(R_{i}^{\prime}, R_{-i}\right)$ and we have

$$
p\left(R_{i}\right) \leq p\left(R_{i}^{\prime}\right) \leq F_{i}\left(R_{i}^{\prime}, R_{-i}\right)<F_{i}\left(R_{i}, R_{-i}\right)
$$

and then with preferences $R_{i}$, agent $i$ has an incentive to declare $R_{i}^{\prime}$. Finally if $p\left(R_{i}\right) \leq$ $F_{i}\left(R_{i}, R_{-i}\right) \leq p\left(R_{i}^{\prime}\right)$, then with preferences $R_{i}^{\prime}$, agent $i$ has an incentive to declare $R_{i}$. Since in all cases, strategy proofness is violated, the supposition is false.

It follows from Lemma 3 that if $\left(R_{i}, R_{-i}\right),\left(R_{i}^{\prime}, R_{-i}\right) \in \mathcal{R}^{N}$ is such that $p\left(R_{i}\right)=p\left(R_{i}^{\prime}\right)$, then $F_{i}\left(R_{i}, R_{-i}\right)=F_{i}\left(R_{i}^{\prime}, R_{-i}\right)$. That is, an agent who does not change his peak can not affect his share.

The following result can be called an "invariance lemma" since it states that even an agent changing his peak, if he does not cross to the other side of his share, can not affect it.

Lemma 4 Let the trade rule $F$ satisfy Pareto optimality and strategy proofness. Let $N \in \mathcal{N}$, $i \in N$, and $\left(R_{i}, R_{-i}\right),\left(R_{i}^{\prime}, R_{-i}\right) \in \mathcal{R}^{N}$. If $p\left(R_{i}\right)<F_{i}\left(R_{i}, R_{-i}\right)$ and $p\left(R_{i}^{\prime}\right) \leq F_{i}\left(R_{i}, R_{-i}\right)$, then $F_{i}\left(R_{i}^{\prime}, R_{-i}\right)=F_{i}\left(R_{i}, R_{-i}\right)$. Similarly if $p\left(R_{i}\right)>F_{i}\left(R_{i}, R_{-i}\right)$ and $p\left(R_{i}^{\prime}\right) \geq F_{i}\left(R_{i}, R_{-i}\right)$, then $F_{i}\left(R_{i}^{\prime}, R_{-i}\right)=F_{i}\left(R_{i}, R_{-i}\right)$.

\footnotetext{
${ }^{17}$ Ching (1994) works on the Sprumont (1991) domain.
} 
Proof. To prove the first statement, suppose $p\left(R_{i}\right)<F_{i}\left(R_{i}, R_{-i}\right), p\left(R_{i}^{\prime}\right) \leq F_{i}\left(R_{i}, R_{-i}\right)$, and $F_{i}\left(R_{i}^{\prime}, R_{-i}\right) \neq F_{i}\left(R_{i}, R_{-i}\right)$. There are two possible cases. If $p\left(R_{i}\right) \leq p\left(R_{i}^{\prime}\right)$ then by Lemma $3, F_{i}\left(R_{i}, R_{-i}\right)<F_{i}\left(R_{i}^{\prime}, R_{-i}\right)$ and with preferences $R_{i}^{\prime}$, agent $i$ has an incentive to declare $R_{i}$. Alternatively if $p\left(R_{i}^{\prime}\right)<p\left(R_{i}\right)$ then by Lemma $3, F_{i}\left(R_{i}^{\prime}, R_{-i}\right)<F_{i}\left(R_{i}, R_{-i}\right)$. Let $R_{i}^{\prime \prime} \in \mathcal{R}$ be such that $p\left(R_{i}^{\prime \prime}\right)=p\left(R_{i}\right)$ and $0 P_{i}^{\prime \prime} F_{i}\left(R_{i}, R_{-i}\right)$. By Lemma $3, F_{i}\left(R_{i}^{\prime \prime}, R_{-i}\right)=F_{i}\left(R_{i}, R_{-i}\right)$. Thus $F_{i}\left(R_{i}^{\prime}, R_{-i}\right)<F_{i}\left(R_{i}^{\prime \prime}, R_{-i}\right)$ and with preferences $R_{i}^{\prime \prime}$, agent $i$ has an incentive to declare $R_{i}^{\prime}$. Since in all cases, strategy proofness is violated, the supposition is false. The proof of the second statement is similar.

\subsection{Uniform Trade Rules}

Our main result shows that only Uniform trade rules satisfy all of our four basic properties.

Note that here, unlike in Proposition 1, we only state strategy proofness.

Theorem 1 A trade rule $F$ satisfies Pareto optimality, strategy proofness, no-envy, and separability in total trade if and only if it is a Uniform trade rule.

Proof. We already showed that the Uniform trade rules satisfy these properties. Conversely, let $F$ be a trade rule satisfying all properties. Let $N=B \cup S \in \mathcal{N}$.

Step 1. For each $K \in\{B, S\},\left(R_{N \backslash K}, R_{K}\right),\left(R_{N \backslash K}, R_{K}^{\prime}\right) \in \mathcal{R}^{B \cup S}, \Omega_{F}\left(R_{N \backslash K}, R_{K}\right)<$ $\sum_{K} p\left(R_{k}\right)$ and $\Omega_{F}\left(R_{N \backslash K}, R_{K}\right)<\sum_{K} p\left(R_{k}^{\prime}\right)$ implies $\Omega_{F}\left(R_{N \backslash K}, R_{K}^{\prime}\right)=\Omega_{F}\left(R_{N \backslash K}, R_{K}\right)$. Similarly, for each $K \in\{B, S\},\left(R_{N \backslash K}, R_{K}\right),\left(R_{N \backslash K}, R_{K}^{\prime}\right) \in \mathcal{R}^{B \cup S}, \Omega_{F}\left(R_{N \backslash K}, R_{K}\right)>\sum_{K} p\left(R_{k}\right)$ and $\Omega_{F}\left(R_{N \backslash K}, R_{K}\right)>\sum_{K} p\left(R_{k}^{\prime}\right)$ implies $\Omega_{F}\left(R_{N \backslash K}, R_{K}^{\prime}\right)=\Omega_{F}\left(R_{N \backslash K}, R_{K}\right)$.

To prove the first statement, let $K \in\{B, S\},\left(R_{N \backslash K}, R_{K}\right),\left(R_{N \backslash K}, R_{K}^{\prime}\right) \in \mathcal{R}^{B \cup S}$, $\Omega_{F}\left(R_{N \backslash K}, R_{K}\right)<\sum_{K} p\left(R_{k}\right)$ and $\Omega_{F}\left(R_{N \backslash K}, R_{K}\right)<\sum_{K} p\left(R_{k}^{\prime}\right)$.

Let $R^{*} \in \mathcal{R}$ be such that $p\left(R^{*}\right)=\frac{\sum_{K} p\left(R_{k}\right)}{|K|}$. By separability in total trade, $\Omega_{F}\left(R_{N \backslash K}, R_{K}^{*}\right)=$ $\Omega_{F}\left(R_{N \backslash K}, R_{K}\right)$. By Pareto optimality and no-envy, for each $k \in K, F_{k}\left(R_{N \backslash K}, R_{K}^{*}\right)=$ $\frac{\Omega_{F}\left(R_{N \backslash K}, R_{K}\right)}{|K|}$. Note that $\frac{\Omega_{F}\left(R_{N \backslash K}, R_{K}\right)}{|K|}<p\left(R^{*}\right)$.

Now let $R^{* *} \in \mathcal{R}$ be such that $p\left(R^{* *}\right)=\frac{\sum_{K} p\left(R_{k}^{\prime}\right)}{|K|}$ and $p\left(R^{*}\right) P^{* *} \frac{\Omega_{F}\left(R_{N \backslash K}, R_{K}\right)}{|K|}$. Since $\Omega_{F}\left(R_{N \backslash K}, R_{K}\right)<\sum_{K} p\left(R_{k}^{\prime}\right)$, we have $\frac{\Omega_{F}\left(R_{N \backslash K}, R_{K}\right)}{|K|}<p\left(R^{* *}\right)$.

Let $K=\{1, \ldots, n\}$. Now for each $i \in K$, we claim

$$
F_{K}\left(R_{N \backslash K}, R_{\{i, \ldots, n\}}^{*}, R_{\{1, \ldots, i-1\}}^{* *}\right)=F_{K}\left(R_{N \backslash K}, R_{\{i+1, \ldots, n\}}^{*}, R_{\{1, \ldots, i\}}^{* *}\right) .{ }^{18}
$$

\footnotetext{
${ }^{18}$ With an abuse of notation, for $i=1$, let $\{1, \ldots, i-1\}=\emptyset$ and for $i=n$, let $\{i+1, \ldots, n\}=\emptyset$.
} 
To prove, note that $F_{K}\left(R_{N \backslash K}, R_{K}^{*}\right)=\left(\frac{\Omega_{F}\left(R_{N \backslash K}, R_{K}\right)}{|K|}\right)_{k \in K}$ and for $i \geq 2$, assume that the statement holds up to agent $i$. Thus for each $k \in K$,

$$
F_{k}\left(R_{N \backslash K}, R_{\{i, \ldots, n\}}^{*}, R_{\{1, \ldots, i-1\}}^{* *}\right)=\frac{\Omega_{F}\left(R_{N \backslash K}, R_{K}\right)}{|K|}<\min \left\{p\left(R^{*}\right), p\left(R^{* *}\right)\right\} .
$$

Then by Lemma $4, F_{i}\left(R_{N \backslash K}, R_{\{i+1, \ldots, n\}}^{*}, R_{\{1, \ldots, i\}}^{* *}\right)=\frac{\Omega_{F}\left(R_{N \backslash K}, R_{K}\right)}{|K|}$. Let $j \in K \backslash\{i\}$. If $R_{j}=R^{* *}$, then ${ }^{19}$ by no-envy $F_{j}\left(R_{N \backslash K}, R_{\{i+1, \ldots, n\}}^{*}, R_{\{1, \ldots, i\}}^{* *}\right)=F_{i}\left(R_{N \backslash K}, R_{\{i+1, \ldots, n\}}^{*}, R_{\{1, \ldots, i\}}^{* *}\right)=$ $\frac{\Omega_{F}\left(R_{N \backslash K}, R_{K}\right)}{|K|}$. Alternatively assume $R_{j}=R^{*}$. If $F_{j}\left(R_{N \backslash K}, R_{\{i+1, \ldots, n\}}^{*}, R_{\{1, \ldots, i\}}^{* *}\right)<\frac{\Omega_{F}\left(R_{N \backslash K}, R_{K}\right)}{|K|}$, then $j$ envies $i$ and if $\frac{\Omega_{F}\left(R_{N \backslash K}, R_{K}\right)}{|K|}<F_{j}\left(R_{N \backslash K}, R_{\{i+1, \ldots, n\}}^{*}, R_{\{1, \ldots, i\}}^{* *}\right)$, since by Pareto optimality, $F_{j}\left(R_{N \backslash K}, R_{\{i+1, \ldots, n\}}^{*}, R_{\{1, \ldots, i\}}^{* *}\right) \leq p\left(R^{*}\right)$, we have $F_{j}\left(R_{N \backslash K}, R_{\{i+1, \ldots, n\}}^{*}, R_{\{1, \ldots, i\}}^{* *}\right) P^{* *} \frac{\Omega_{F}\left(R_{N \backslash K}, R_{K}\right)}{|K|}$, that is, $i$ envies $j$. Thus

$$
F_{j}\left(R_{N \backslash K}, R_{\{i+1, \ldots, n\}}^{*}, R_{\{1, \ldots, i\}}^{* *}\right)=\frac{\Omega_{F}\left(R_{N \backslash K}, R_{K}\right)}{|K|} .
$$

By this claim we have, for each $i \in K$,

$$
\Omega_{F}\left(R_{N \backslash K}, R_{\{i, \ldots, n\}}^{*}, R_{\{1, \ldots, i-1\}}^{* *}\right)=\Omega_{F}\left(R_{N \backslash K}, R_{\{i+1, \ldots, n\}}^{*}, R_{\{1, \ldots, i\}}^{* *}\right) .
$$

This implies $\Omega_{F}\left(R_{N \backslash K}, R_{K}^{* *}\right)=\Omega_{F}\left(R_{N \backslash K}, R_{K}\right)$. Finally note that $\sum_{K} p\left(R_{k}^{\prime}\right)=|K| p\left(R^{* *}\right)$. This, by separability in total trade, implies that $\Omega_{F}\left(R_{N \backslash K}, R_{K}^{\prime}\right)=\Omega_{F}\left(R_{N \backslash K}, R_{K}\right)$.

The proof of the second statement of this step is similar.

Step 2. For each $\left(R_{N \backslash K}, R_{K}\right),\left(R_{N \backslash K}, R_{K}^{\prime}\right) \in \mathcal{R}^{B \cup S}, \Omega_{F}\left(R_{N \backslash K}, R_{K}\right) \leq \sum_{K} p\left(R_{k}\right)$ and $\sum_{N \backslash K} p\left(R_{k}\right) \leq \sum_{K} p\left(R_{k}^{\prime}\right) \leq \Omega_{F}\left(R_{N \backslash K}, R_{K}\right)$ implies $\Omega_{F}\left(R_{N \backslash K}, R_{K}^{\prime}\right)=\sum_{K} p\left(R_{k}^{\prime}\right)$. Similarly, for each $\left(R_{N \backslash K}, R_{K}\right),\left(R_{N \backslash K}, R_{K}^{\prime}\right) \in \mathcal{R}^{B \cup S}, \Omega_{F}\left(R_{N \backslash K}, R_{K}\right) \geq \sum_{K} p\left(R_{k}\right)$ and $\sum_{N \backslash K} p\left(R_{k}\right) \geq$ $\sum_{K} p\left(R_{k}^{\prime}\right) \geq \Omega_{F}\left(R_{N \backslash K}, R_{K}\right)$ implies $\Omega_{F}\left(R_{N \backslash K}, R_{K}^{\prime}\right)=\sum_{K} p\left(R_{k}^{\prime}\right)$.

To prove the first statement, let $\left(R_{N \backslash K}, R_{K}\right),\left(R_{N \backslash K}, R_{K}^{\prime}\right) \in \mathcal{R}^{B \cup S}, \Omega_{F}\left(R_{N \backslash K}, R_{K}\right) \leq$ $\sum_{K} p\left(R_{k}\right)$ and $\sum_{N \backslash K} p\left(R_{k}\right) \leq \sum_{K} p\left(R_{k}^{\prime}\right) \leq \Omega_{F}\left(R_{N \backslash K}, R_{K}\right)$. Note that by Pareto optimality $\Omega_{F}\left(R_{N \backslash K}, R_{K}^{\prime}\right) \leq \sum_{K} p\left(R_{k}^{\prime}\right)$. Suppose $\Omega_{F}\left(R_{N \backslash K}, R_{K}^{\prime}\right)<\sum_{K} p\left(R_{k}^{\prime}\right)$. Then by Step 1, $\Omega_{F}\left(R_{N \backslash K}, R_{K}^{\prime}\right)=\Omega_{F}\left(R_{N \backslash K}, R_{K}\right)$, a contradiction.

The proof of the second statement of this step is similar.

Step 3. Determining the functions $\beta$ and $\sigma$.

For $c \in \mathbb{R}_{+}$, let $R^{c} \in \mathcal{R}$ be such that $p\left(R^{c}\right)=c$ and let $R_{N^{\prime}}^{c}=\left(R^{c}\right)_{i \in N^{\prime}}$. Now for $d \in \mathbb{R}_{+}$, consider $\left(R_{B}^{0}, R_{S}^{d}\right) \in \mathcal{R}^{B \cup S}$ and

\footnotetext{
${ }^{19}$ Note that we use $R_{j}$ to denote the "generic" preference relation of agent $j$. On the other hand, $R^{* *}$ denotes a particular preference relation defined above.
} 
1. if there is $d^{*} \in \mathbb{R}_{+}$such that $d^{*}|S|>\Omega_{F}\left(R_{B}^{0}, R_{S}^{d^{*}}\right)$, let $\beta(B \cup S)=\Omega_{F}\left(R_{B}^{0}, R_{S}^{d^{*}}\right)$,

2. if for each $d \in \mathbb{R}_{+}, d|S|=\Omega_{F}\left(R_{B}^{0}, R_{S}^{d}\right)$, let $\beta(B \cup S)=\infty$.

Similarly obtain $\sigma(B \cup S)$ by using the profiles $\left(R_{B}^{c^{*}}, R_{S}^{0}\right) \in \mathcal{R}^{B \cup S}$ for $c^{*} \in \mathbb{R}_{+}$. If no such $c^{*}$ exists, set $\sigma(B \cup S)=\infty$.

Step 4. If $\left(R_{B}, R_{S}\right) \in \mathcal{R}^{B \cup S}$ satisfies $\sum_{B} p\left(R_{k}\right) \leq \sum_{S} p\left(R_{k}\right)$, then

$$
\Omega_{F}\left(R_{B}, R_{S}\right)=\operatorname{median}\left\{\beta(B \cup S), \sum_{B} p\left(R_{k}\right), \sum_{S} p\left(R_{k}\right)\right\}
$$

If $\sum_{B} p\left(R_{k}\right)=\sum_{S} p\left(R_{k}\right)$, the statement trivially holds. So let $\sum_{B} p\left(R_{k}\right)<\sum_{S} p\left(R_{k}\right)$.

First assume there is $d^{*} \in \mathbb{R}_{+}$such that $d^{*}|S|>\Omega_{F}\left(R_{B}^{0}, R_{S}^{d^{*}}\right)$. Then by Step $3, \beta(B \cup S)=$ $\Omega_{F}\left(R_{B}^{0}, R_{S}^{d^{*}}\right)$.

There are three possible cases.

Case 1. $\sum_{B} p\left(R_{k}\right)<\beta(B \cup S)<\sum_{S} p\left(R_{k}\right)$.

Then since $0|B|<\beta(B \cup S)=\Omega_{F}\left(R_{B}^{0}, R_{S}^{d^{*}}\right)<d^{*}|S|$, applying Step 1 twice, we get $\Omega_{F}\left(R_{B}^{0}, R_{S}^{d^{*}}\right)=\Omega_{F}\left(R_{B}, R_{S}^{d^{*}}\right)=\Omega_{F}\left(R_{B}, R_{S}\right)$.

Case 2. $\beta(B \cup S) \leq \sum_{B} p\left(R_{k}\right)<\sum_{S} p\left(R_{k}\right)$.

Then since $0|B| \leq \beta(B \cup S)=\Omega_{F}\left(R_{B}^{0}, R_{S}^{d^{*}}\right)<d^{*}|S|$, applying Step 1 to $S$, we get $\Omega_{F}\left(R_{B}^{0}, R_{S}^{d^{*}}\right)=\Omega_{F}\left(R_{B}^{0}, R_{S}\right)$ and applying Step 2 to $B$, we get $\Omega_{F}\left(R_{B}, R_{S}\right)=\sum_{B} p\left(R_{k}\right)$.

Case 3. $\sum_{B} p\left(R_{k}\right)<\sum_{S} p\left(R_{k}\right) \leq \beta(B \cup S)$.

Then since $0|B|<\beta(B \cup S)=\Omega_{F}\left(R_{B}^{0}, R_{S}^{d^{*}}\right)<d^{*}|S|$, applying Step 1 to $B$, we get $\Omega_{F}\left(R_{B}^{0}, R_{S}^{d^{*}}\right)=\Omega_{F}\left(R_{B}, R_{S}^{d^{*}}\right)$ and applying Step 2 to $S$, we get $\Omega_{F}\left(R_{B}, R_{S}\right)=\sum_{S} p\left(R_{k}\right)$.

Next assume that for each $d \in \mathbb{R}_{+}, d|S|=\Omega_{F}\left(R_{B}^{0}, R_{S}^{d}\right)$. Then by Step $3, \beta(B \cup S)=\infty$. Let $d>0$ be such that $d|S|=\sum_{S} p\left(R_{k}\right)$. Then $\Omega_{F}\left(R_{B}^{0}, R_{S}^{d}\right)=\sum_{S} p\left(R_{k}\right)>0$. Thus by Step $1, \Omega_{F}\left(R_{B}, R_{S}^{d}\right)=\sum_{S} p\left(R_{k}\right)$. Finally by Step $2 \Omega_{F}\left(R_{B}, R_{S}\right)=\sum_{S} p\left(R_{k}\right)$.

Since in all cases $\Omega_{F}\left(R_{B}, R_{S}\right)=\operatorname{median}\left\{\beta(B \cup S), \sum_{B} p\left(R_{k}\right), \sum_{S} p\left(R_{k}\right)\right\}$, the proof is complete.

Step 5. If $\left(R_{B}, R_{S}\right) \in \mathcal{R}^{B \cup S}$ satisfies $\sum_{B} p\left(R_{k}\right) \geq \sum_{S} p\left(R_{k}\right)$, then

$$
\Omega_{F}\left(R_{B}, R_{S}\right)=\operatorname{median}\left\{\sigma(B \cup S), \sum_{B} p\left(R_{k}\right), \sum_{S} p\left(R_{k}\right)\right\}
$$

The proof is similar to that of Step 4 .

Step 6. $F=U T^{\beta \sigma}$ 
Suppose $F_{K}\left(R_{N}\right) \neq U T_{K}^{\beta \sigma}\left(R_{N}\right)$ for some $R_{N} \in \mathcal{R}^{N}$ and $K \in\{B, S\}$. By steps 4 and 5 , $\Omega_{F}\left(R_{N}\right)=\Omega_{U T^{\beta \sigma}}\left(R_{N}\right)$ and by our supposition, $\sum_{K} p\left(R_{k}\right) \neq \Omega_{F}\left(R_{N}\right)$.

First assume that $\sum_{K} p\left(R_{k}\right)>\Omega_{F}\left(R_{N}\right)$. Since $F_{K}\left(R_{N}\right) \neq U T_{K}^{\beta \sigma}\left(R_{N}\right)$, there is $i \in K$ such that

$$
F_{i}\left(R_{N}\right)<U T_{i}^{\beta \sigma}\left(R_{N}\right) \leq p\left(R_{i}\right) .
$$

Let $R_{i}^{\prime} \in \mathcal{R}$ be such that $p\left(R_{i}^{\prime}\right)=p\left(R_{i}\right)$ and for each $x>F_{i}\left(R_{B}, R_{S}\right), x P_{i}^{\prime} F_{i}\left(R_{B}, R_{S}\right)$. By Lemma 3,

$$
F_{i}\left(R_{i}^{\prime}, R_{-i}\right)<U T_{i}^{\beta \sigma}\left(R_{i}^{\prime}, R_{-i}\right) \leq p\left(R_{i}^{\prime}\right) .
$$

Now since $\sum_{K} F_{k}\left(R_{N}\right)=\sum_{K} U T_{k}^{\beta \sigma}\left(R_{N}\right)$, there is $j \in K$ such that $U T_{j}^{\beta \sigma}\left(R_{i}^{\prime}, R_{-i}\right)<$ $F_{j}\left(R_{i}^{\prime}, R_{-i}\right)$. Thus $U T_{j}^{\beta \sigma}\left(R_{i}^{\prime}, R_{-i}\right)<p\left(R_{j}\right)$ and by definition of $U T^{\beta \sigma}, U T_{i}^{\beta \sigma}\left(R_{i}^{\prime}, R_{-i}\right) \leq$ $U T_{j}^{\beta \sigma}\left(R_{i}^{\prime}, R_{-i}\right)$. Then $F_{i}\left(R_{i}^{\prime}, R_{-i}\right)<F_{j}\left(R_{i}^{\prime}, R_{-i}\right)$ and with preferences $R_{i}^{\prime}$, agent $i$ envies agent $j$, a contradiction.

The proof of the second case where $\sum_{K} p\left(R_{k}\right)<\Omega_{F}\left(R_{N}\right)$ is similar.

The properties of Theorem 1 are logically independent. First, the simple rule which always chooses zero trade satisfies all properties but Pareto optimality. Second, the rule which always clears the short side of the market and rations the long side proportionally (that is, each agent gets a constant proportion of his peak) satisfies all properties but strategy proofness. Third, the rule which always clears the short side of the market and rations the long side by a priority order (according to which agents are served sequentially until the volume of trade is exhausted) satisfies all properties but no-envy. Finally, the following is an example of a rule that satisfies all properties but separability in total trade. ${ }^{20}$ Let $N=\{1,2,3\}$ and $K=\{1,2\}$. Let

$$
\Omega_{F}\left(R_{1}, R_{2}, R_{3}\right)=\text { median }\left\{p\left(R_{3}\right), 2 p\left(R_{1}\right), 2 p\left(R_{2}\right)\right\} \text {. }
$$

That is, given a market where agents 1 and 2 are on one side and Agent 3 is on the other side, the volume of trade is determined as a median of the three quantities above. Then let $F$ determine the shares of agents 1 and 2 similar to the Uniform trade rules (see Equation 1). Finally, let $F$ coincide with an arbitrary Uniform trade rule for every $(B \cup S) \in \mathcal{N}$ with $|B \cup S| \neq 3$.

In what follows, we characterize those Uniform trade rules that satisfy additional properties.

\footnotetext{
${ }^{20}$ This rule is in fact coalitional strategy proof.
} 


\subsection{Anonymity and Strong Separability}

In this subsection, we analyze the implications of in-group anonymity in total trade, betweengroup anonymity in total trade, and strong separability. We first analyze their individual implications. Then we characterize their implications as a group. We start with the anonymity properties.

Corollary 1 Let $F$ be a trade rule that satisfies Pareto optimality, strategy proofness, noenvy, and separability in total trade. Then

( $i$ ) F satisfies in-group anonymity in total trade if and only if it is a Uniform trade rule UT $T^{\beta \sigma}$ where for each $(B \cup S),\left(B^{\prime} \cup S^{\prime}\right) \in \mathcal{N}$ such that $|B|=\left|B^{\prime}\right|$ and $|S|=\left|S^{\prime}\right|, \beta(B \cup S)=\beta\left(B^{\prime} \cup S^{\prime}\right)$ and $\sigma(B \cup S)=\sigma\left(B^{\prime} \cup S^{\prime}\right)$,

(ii) assuming $|\mathcal{B}|=|\mathcal{S}|, F$ satisfies between-group anonymity in total trade if and only if it is a Uniform trade rule $U T^{\beta \sigma}$ where for each $(B \cup S),\left(B^{\prime} \cup S^{\prime}\right) \in \mathcal{N}$ such that $|B|=\left|S^{\prime}\right|$ and $|S|=\left|B^{\prime}\right|, \beta(B \cup S)=\sigma\left(B^{\prime} \cup S^{\prime}\right)$ and $\sigma(B \cup S)=\beta\left(B^{\prime} \cup S^{\prime}\right)$.

Proof. By Theorem 1, F is a Uniform trade rule $U T^{\beta \sigma}$. The proof of the first statement is trivial and omitted. For the second statement, first assume that $U T^{\beta \sigma}$ is between-group anonymous in total trade. Let $(B \cup S),\left(B^{\prime} \cup S^{\prime}\right) \in \mathcal{N}$ be such that $|B|=\left|S^{\prime}\right|$ and $|S|=\left|B^{\prime}\right|$. Let $\left(R_{B}, R_{S}\right) \in \mathcal{R}^{B \cup S}$ and $\left(R_{B^{\prime}}^{\prime}, R_{S^{\prime}}^{\prime}\right) \in \mathcal{R}^{B^{\prime} \cup S^{\prime}}$ be such that $R_{B}=R_{S^{\prime}}^{\prime}, R_{S}=R_{B^{\prime}}^{\prime}$, and $\sum_{B} p\left(R_{k}\right)<\beta(B \cup S)<\sum_{S} p\left(R_{k}\right)$. Then $\Omega_{U T^{\beta \sigma}}\left(R_{B}, R_{S}\right)=\beta(B \cup S)$ and $\Omega_{U T^{\beta \sigma}}\left(R_{B^{\prime}}^{\prime}, R_{S^{\prime}}^{\prime}\right)=$ $\sigma\left(B^{\prime} \cup S^{\prime}\right)$. By between-group anonymity in total trade $\Omega_{U T^{\beta \sigma}}\left(R_{B}, R_{S}\right)=\Omega_{U T^{\beta \sigma}}\left(R_{B^{\prime}}^{\prime}, R_{S^{\prime}}^{\prime}\right)$. Thus $\beta(B \cup S)=\sigma\left(B^{\prime} \cup S^{\prime}\right)$. One similarly obtains $\sigma(B \cup S)=\beta\left(B^{\prime} \cup S^{\prime}\right)$.

Now assume that $U T^{\beta \sigma}$ satisfies the given property. Let $\left(R_{B}, R_{S}\right) \in \mathcal{R}^{B \cup S}$ and $\phi \in \Phi$. Without loss of generality assume $\sum_{B} p\left(R_{k}\right) \leq \sum_{S} p\left(R_{k}\right)$. Then,

$$
\Omega_{U T^{\beta \sigma}}\left(R_{B}, R_{S}\right)=\operatorname{median}\left\{\beta(B \cup S), \sum_{B} p\left(R_{k}\right), \sum_{S} p\left(R_{k}\right)\right\}
$$

By the given property $\beta(B \cup S)=\sigma(\phi(S) \cup \phi(B))$. Also, $\sum_{B} p\left(R_{k}\right)=\sum_{\phi(B)} p\left(R_{k}^{\phi}\right)$ and $\sum_{S} p\left(R_{k}\right)=\sum_{\phi(S)} p\left(R_{k}^{\phi}\right)$. Thus $\sum_{\phi(B)} p\left(R_{k}^{\phi}\right) \leq \sum_{\phi(S)} p\left(R_{k}^{\phi}\right)$ and

$$
\begin{aligned}
\Omega_{U T^{\beta \sigma}}\left(R_{\phi(S)}^{\phi}, R_{\phi(B)}^{\phi}\right) & =\operatorname{median}\left\{\sigma(\phi(S) \cup \phi(B)), \sum_{\phi(S)} p\left(R_{k}^{\phi}\right), \sum_{\phi(B)} p\left(R_{k}^{\phi}\right)\right\} \\
& =\Omega_{U T^{\beta \sigma}}\left(R_{B}, R_{S}\right) .
\end{aligned}
$$


Since between-group anonymity in total trade is stronger than in-group anonymity in total trade, Property $(i i)$ in Corollary 1 implies Property $(i)$. The first part of this result states that in-group anonymity in total trade makes $\beta$ and $\sigma$ only dependent on the number of buyers and sellers. According to the second part, between-group anonymity in total trade additionally requires the treatment of buyers in a $k$-buyer, $l$-seller problem to be the same as the treatment of sellers in an $l$-buyer, $k$-seller problem.

Next we analyze the implications of strong separability in total trade. We start with the much larger class of all Pareto optimal and strategy proof trade rules.

Proposition 2 If a trade rule $F$ satisfies Pareto optimality, strategy proofness, and strong separability in total trade, then there is $c_{\beta}, c_{\sigma} \in \mathbb{R}_{+} \cup\{\infty\}$ such that for each $\left(R_{B}, R_{S}\right) \in \mathcal{M}$

$$
\Omega_{F}\left(R_{B}, R_{S}\right)=\left\{\begin{array}{lll}
\operatorname{median}\left\{c_{\beta}, \sum_{B} p\left(R_{i}\right), \sum_{S} p\left(R_{i}\right)\right\} & \text { if } \quad & \left.\sum_{B} p\left(R_{i}\right) \leq \sum_{S} p\left(R_{i}\right)\right\}, \\
\operatorname{median}\left\{c_{\sigma}, \sum_{B} p\left(R_{i}\right), \sum_{S} p\left(R_{i}\right)\right\} & \text { if } \quad & \left.\sum_{B} p\left(R_{i}\right) \geq \sum_{S} p\left(R_{i}\right)\right\} .
\end{array}\right.
$$

Proof. For $x \in \mathbb{R}_{+}$, let $R^{x} \in \mathcal{R}$ be such that $p\left(R^{x}\right)=x$. Fix $b \in \mathcal{B}$ and $s \in \mathcal{S}$.

If there is $x^{*} \in \mathbb{R}_{+}$such that $\Omega_{F}\left(R_{b}^{0}, R_{s}^{x^{*}}\right)<x^{*}$, let $c_{\beta}=\Omega_{F}\left(R_{b}^{0}, R_{s}^{x^{*}}\right)$. Otherwise, let $c_{\beta}=\infty$. Similarly if there is $y^{*} \in \mathbb{R}_{+}$such that $\Omega_{F}\left(R_{b}^{y^{*}}, R_{s}^{0}\right)<y^{*}$, let $c_{\sigma}=\Omega_{F}\left(R_{b}^{y^{*}}, R_{s}^{0}\right)$; otherwise, let $c_{\sigma}=\infty$.

Step 1. For each $\left(R_{b}, R_{s}\right) \in \mathcal{R}^{\{b, s\}}$, if $p\left(R_{b}\right) \leq p\left(R_{s}\right)$, then $\Omega_{F}\left(R_{b}, R_{s}\right)=\operatorname{median}\left\{c_{\beta}, p\left(R_{b}\right), p\left(R_{s}\right)\right\}$ and if $p\left(R_{s}\right) \leq p\left(R_{b}\right)$, then $\Omega_{F}\left(R_{b}, R_{s}\right)=\operatorname{median}\left\{c_{\sigma}, p\left(R_{b}\right), p\left(R_{s}\right)\right\}$.

Let $\left(R_{b}, R_{s}\right) \in \mathcal{R}^{\{b, s\}}$ and assume that $p\left(R_{b}\right) \leq p\left(R_{s}\right)$ (the proof for the alternative case is similar). Note that $\Omega_{F}\left(R_{b}, R_{s}\right)=F_{b}\left(R_{b}, R_{s}\right)=F_{s}\left(R_{b}, R_{s}\right)$.

Claim 1: If $p\left(R_{b}\right)<c_{\beta}<p\left(R_{s}\right)$, then $\Omega_{F}\left(R_{b}, R_{s}\right)=c_{\beta}=\operatorname{median}\left\{c_{\beta}, p\left(R_{b}\right), p\left(R_{s}\right)\right\}$.

Too see this note that $p\left(R_{b}^{0}\right)<c_{\beta}=F_{b}\left(R_{b}^{0}, R_{s}^{x^{*}}\right)=F_{s}\left(R_{b}^{0}, R_{s}^{x^{*}}\right)<p\left(R_{s}^{x^{*}}\right)$. Thus by Lemma $4, c_{\beta}=F_{b}\left(R_{b}^{0}, R_{s}^{x^{*}}\right)=F_{b}\left(R_{b}, R_{s}^{x^{*}}\right)$ and $F_{s}\left(R_{b}, R_{s}^{x^{*}}\right)=F_{s}\left(R_{b}, R_{s}\right)=c_{\beta}$. This implies $\Omega_{F}\left(R_{b}, R_{s}\right)=c_{\beta}$.

Claim 2: If $c_{\beta} \leq p\left(R_{b}\right) \leq p\left(R_{s}\right)$, then $\Omega_{F}\left(R_{b}, R_{s}\right)=p\left(R_{b}\right)=\operatorname{median}\left\{c_{\beta}, p\left(R_{b}\right), p\left(R_{s}\right)\right\}$.

If $p\left(R_{b}\right)=p\left(R_{s}\right)$, the statement trivially holds. So let $p\left(R_{b}\right)<p\left(R_{s}\right)$. Note that by Lemma $4, \Omega_{F}\left(R_{b}^{0}, R_{s}^{x^{*}}\right)=\Omega_{F}\left(R_{b}^{0}, R_{s}\right)=c_{\beta}$. Suppose $\Omega_{F}\left(R_{b}, R_{s}\right)>p\left(R_{b}\right)$. Note that $\Omega_{F}\left(R_{b}, R_{s}\right)=F_{b}\left(R_{b}, R_{s}\right)$. Let $R_{b}^{\prime} \in \mathcal{R}$ be such that $p\left(R_{b}^{\prime}\right)=p\left(R_{b}\right)$ and $c_{\beta} P_{b}^{\prime} F_{b}\left(R_{b}, R_{s}\right)$. By Lemma $3, F_{b}\left(R_{b}^{\prime}, R_{s}\right)=F_{b}\left(R_{b}, R_{s}\right)$. Thus $c_{\beta}=F\left(R_{b}^{0}, R_{s}\right) P_{b}^{\prime} F_{b}\left(R_{b}^{\prime}, R_{s}\right)$ violates strategy proofness. This implies $\Omega_{F}\left(R_{b}, R_{s}\right)=p\left(R_{b}\right)$. 
Claim 3: If $p\left(R_{b}\right) \leq p\left(R_{s}\right) \leq c_{\beta}$, then $\Omega_{F}\left(R_{b}, R_{s}\right)=p\left(R_{s}\right)=\operatorname{median}\left\{c_{\beta}, p\left(R_{b}\right), p\left(R_{s}\right)\right\}$.

The proof Claim 3 is similar to that of Claim 2.

Step 2. For each $B \cup S \in \mathcal{N}$ and $\left(R_{B}, R_{S}\right) \in \mathcal{R}^{N}$, if $\sum_{B} p\left(R_{k}\right) \leq \sum_{S} p\left(R_{k}\right)$, then $\Omega_{F}\left(R_{b}, R_{s}\right)=\operatorname{median}\left\{c_{\beta}, \sum_{B} p\left(R_{k}\right), \sum_{S} p\left(R_{k}\right)\right\}$ and if $p\left(R_{s}\right) \leq p\left(R_{b}\right)$, then

$$
\Omega_{F}\left(R_{b}, R_{s}\right)=\operatorname{median}\left\{c_{\sigma}, \sum_{B} p\left(R_{k}\right), \sum_{B} p\left(R_{k}\right)\right\}
$$

Assume that $\sum_{B} p\left(R_{k}\right) \leq \sum_{S} p\left(R_{k}\right)$ (the proof for the alternative case is similar). Let $R_{b}^{*}, R_{s}^{*} \in \mathcal{R}$ be such that $p\left(R_{b}^{*}\right)=\sum_{B} p\left(R_{k}\right)$ and $p\left(R_{s}^{*}\right)=\sum_{S} p\left(R_{k}\right)$. By strong separability in total trade, $\Omega_{F}\left(R_{B}, R_{S}\right)=\Omega_{F}\left(R_{b}^{*}, R_{s}^{*}\right)$ and by Step $1, \Omega_{F}\left(R_{b}^{*}, R_{s}^{*}\right)=\operatorname{median}\left\{c_{\beta}, p\left(R_{b}^{*}\right), p\left(R_{s}^{*}\right)\right\}$. Combining the two statements gives the desired conclusion.

The following remark summarizes the implications of strong separability in total trade on Uniform trade rules. It trivially follows from Proposition 2 and Theorem 1.

Remark 1 A trade rule $F$ satisfies Pareto optimality, strategy proofness, no-envy, and strong separability in total trade if and only if it is a Uniform trade rule $U T^{\beta \sigma}$ where there is $c_{\beta}, c_{\sigma} \in \mathbb{R}_{+} \cup\{\infty\}$ such that for all $(B \cup S) \in N, \beta(B \cup S)=c_{\beta}$ and $\sigma(B \cup S)=c_{\sigma}$.

We next discuss the joint implications of anonymity and separability properties. Strongly separable Uniform trade rules treat the buyers (respectively, the sellers) the same way in every problem. Note that thus strong separability not only implies separability but also in-group anonymity in total trade. Strongly separable rules that additionally satisfy betweengroup anonymity in total trade treat all problems the same way and make no difference between buyers and sellers. This observation trivially follows from Corollary 1 and Proposition 2. It leads to the following remark.

Remark 2 Let $|\mathcal{B}|=|\mathcal{S}|$. A trade rule $F$ satisfies Pareto optimality, strategy proofness, noenvy, strong separability in total trade, and between-group anonymity in total trade if and only if it is a Uniform trade rule $U T^{\beta \sigma}$ such that for some $c \in \mathbb{R}_{+} \cup\{\infty\}, \beta(B \cup S)=\sigma(B \cup S)=c$ for all $(B \cup S) \in N$. 


\subsection{Renegotiation Proofness and Voluntary Trade}

In this subsection, we analyze the implications of two stability properties that require an allocation not to be blocked either by a pair of agents (as in renegotiation proofness) or by a single agent (as in voluntary trade). We first characterize Uniform trade rules that are renegotiation proof.

Corollary 2 A trade rule $F$ satisfies Pareto optimality, strategy proofness, no-envy, separability in total trade, and renegotiation proofness if and only if it is a Uniform trade rule $U T^{\beta \sigma}$ where for each $(B \cup S) \in \mathcal{N},|B|<|S|$ implies $\beta(B \cup S) \in\{0, \infty\}$ and $|S|<|B|$ implies $\sigma(B \cup S) \in\{0, \infty\}$.

Proof. By Theorem 1, F is a Uniform trade rule $U T^{\beta \sigma}$. For the only if part suppose there is $(B \cup S) \in \mathcal{N}$ such that $|B|<|S|$ and $\beta(B \cup S) \in(0, \infty)$. Let $R^{c} \in \mathcal{R}$ be such that $p\left(R^{c}\right)=c \in\left(\frac{\beta(B \cup S)}{|S|}, \frac{\beta(B \cup S)}{|B|}\right)$. Let $\left(R_{B}, R_{S}\right) \in \mathcal{R}^{B \cup S}$ be such that for each $i \in B \cup S$, $R_{i}=R^{c}$. Then,

$$
\Omega_{U T^{\beta \sigma}}\left(R_{B}, R_{S}\right)=\operatorname{median}\{\beta(B \cup S), c|B|, c|S|\}=\beta(B \cup S) .
$$

By no-envy and Pareto optimality, for each $i \in B, U T_{i}^{\beta \sigma}\left(R_{B}, R_{S}\right)=\frac{\beta(B \cup S)}{|B|}$ and for each $j \in$ $S, U T_{j}^{m}\left(R_{B}, R_{S}\right)=\frac{\beta(B \cup S)}{|S|}$. This implies, there is $i \in B$ and $j \in S$ such that $c P_{i} U T_{i}^{\beta \sigma}\left(R_{B}, R_{S}\right)$ and $c P_{j} U T_{j}^{\beta \sigma}\left(R_{B}, R_{S}\right)$ and therefore that $U T^{\beta \sigma}$ is not renegotiation proof. Thus, $\beta(B \cup S)=$ 0 or $\beta(B \cup S)=\infty$. A similar argument applies for the case $|S|<|B|$ and $\sigma(B \cup S)$.

The if part is as follows. If $(B \cup S) \in \mathcal{N}$ is such that $\beta(B \cup S), \sigma(B \cup S) \in\{0, \infty\}$, then for each $\left(R_{B}, R_{S}\right) \in \mathcal{R}^{B \cup S}$, there is $K \in\{B, S\}$ such that $\Omega_{U T^{\beta \sigma}}\left(R_{B}, R_{S}\right)=\sum_{i \in K} p\left(R_{i}\right)$ and thus, $U T_{i}^{\beta \sigma}\left(R_{B}, R_{S}\right)=p\left(R_{i}\right)$ for each $i \in K$. In this case, no member of $K$ is better-off by joining a blocking pair and therefore, renegotiation is not possible.

Next let $(B \cup S) \in \mathcal{N}$ be such that $|B| \geq|S|$ and $\beta(B \cup S) \in(0, \infty)$. Let $\left(R_{B}, R_{S}\right) \in$ $\mathcal{R}^{B \cup S}$ be such that $\sum_{i \in B} p\left(R_{i}\right)<\beta(B \cup S)<\sum_{i \in S} p\left(R_{i}\right)$ (otherwise, one group gets its peak and has no incentive to renegotiate). Then, $\Omega_{U T^{\beta \sigma}}\left(R_{B}, R_{S}\right)=\beta(B \cup S)$ and for each $i \in B, U T_{i}^{\beta \sigma}\left(R_{B}, R_{S}\right)=\max \left\{\rho, p\left(R_{i}\right)\right\}$ where $\rho \in \mathbb{R}_{+}$satisfies $\sum_{B} \max \left\{\rho, p\left(R_{k}\right)\right\}=$ $\beta(B \cup S)$. Similarly for each $j \in S, U T_{j}^{\beta \sigma}\left(R_{B}, R_{S}\right)=\min \left\{\lambda, p\left(R_{j}\right)\right\}$ where $\lambda \in \mathbb{R}_{+}$satisfies $\sum_{S} \min \left\{\lambda, p\left(R_{k}\right)\right\}=\beta(B \cup S)$. This implies $\lambda \geq \frac{\beta(B \cup S)}{|S|}, \rho \leq \frac{\beta(B \cup S)}{|B|}$ and thus, $\rho \leq \lambda$. Now suppose there is a blocking pair $(i, j) \in B \times S$. Since neither $i$ nor $j$ can get his peak,

$$
p\left(R_{i}\right)<U T_{i}^{\beta \sigma}\left(R_{B}, R_{S}\right)=\rho \leq \lambda=U T_{j}^{\beta \sigma}\left(R_{B}, R_{S}\right)<p\left(R_{j}\right) .
$$


For both agents to be strictly better off at some $r \in \mathbb{R}_{+}$, we must have $r<U T_{i}^{\beta \sigma}\left(R_{B}, R_{S}\right)$ and $r>U T_{j}^{\beta \sigma}\left(R_{B}, R_{S}\right)$. This implies $r<U T_{i}^{\beta \sigma}\left(R_{B}, R_{S}\right) \leq U T_{j}^{\beta \sigma}\left(R_{B}, R_{S}\right)<r$, a contradiction. Thus $U T^{\beta \sigma}$ is renegotiation proof.

It is interesting to observe that renegotiation proofness has no implications on problems with an equal number of buyers and sellers while its implications on the remaining problems are quite strong. Let us also note that a stronger version of renegotiation proofness which allows blocking pairs where one agent is indifferent (while, of course the other is strictly better-off) is violated by all Uniform trade rules. On the other hand, strenghtening renegotiation proofness by allowing larger (than two-agent) coalitions to form has no effect on the conclusion of Corollary $2 .^{21}$

We next analyze the implications of voluntary trade. We start with the much larger class of all Pareto optimal and strategy proof trade rules.

Proposition 3 If a trade rule $F$ satisfies Pareto optimality, strategy proofness, and voluntary trade, then for each $\left(R_{B}, R_{S}\right) \in \mathcal{M}, \Omega_{F}\left(R_{B}, R_{S}\right)=\min \left\{\sum_{B} p\left(R_{k}\right), \sum_{S} p\left(R_{k}\right)\right\}$.

Proof. Let $\left(R_{B}, R_{S}\right) \in \mathcal{M}$ and without loss of generality assume that $\sum_{B} p\left(R_{k}\right) \leq$ $\sum_{S} p\left(R_{k}\right)$. By Pareto optimality, $\sum_{B} p\left(R_{k}\right) \leq \Omega_{F}\left(R_{B}, R_{S}\right) \leq \sum_{S} p\left(R_{k}\right)$. Suppose $\sum_{B} p\left(R_{k}\right)<$ $\Omega_{F}\left(R_{B}, R_{S}\right)$. Then there is $i \in B$ such that $p\left(R_{i}\right)<F_{i}\left(R_{B}, R_{S}\right)$. Let $R_{i}^{\prime} \in \mathcal{R}$ be such that $p\left(R_{i}^{\prime}\right)=p\left(R_{i}\right)$ and $0 P_{i}^{\prime} F_{i}\left(R_{B}, R_{S}\right)$. By Lemma $3, F_{i}\left(R_{B \backslash i}, R_{i}^{\prime}, R_{S}\right)=F_{i}\left(R_{B}, R_{S}\right)$ and thus $0 P_{i}^{\prime} F_{i}\left(R_{B \backslash i}, R_{i}^{\prime}, R_{S}\right)$, violating voluntary trade.

The following remark summarizes the implications of voluntary trade on Uniform trade rules. It trivially follows from Proposition 3 and Theorem 1.

Remark 3 A trade rule $F$ satisfies Pareto optimality, strategy proofness, no-envy, and voluntary trade if and only if it is a Uniform trade rule $U T^{\beta \sigma}$ such that $\beta(B \cup S)=\sigma(B \cup S)=$ 0 for all $(B \cup S) \in \mathcal{N}$.

\footnotetext{
${ }^{21}$ Formally, all renegotiation proof Uniform trade rules satisfy the following property: a trade rule $F$ is strong renegotiation proof if for each $\left(R_{B}, R_{S}\right) \in \mathcal{M}$ there is no $S^{\prime} \subset S, B^{\prime} \subset B$, and $z \in Z\left(B^{\prime} \cup S^{\prime}\right)$ such that $z_{i} P_{i} F_{i}\left(R_{B}, R_{S}\right)$ for each $i \in B^{\prime} \cup S^{\prime}$.
} 


\section{Conclusions}

In this section, we list some open questions. First, our model is motivated by a production economy. We pick a market there that is in disequilibrium, isolate it from other related markets, and then produce a trade vector for it. In doing this, our considerations are at the micro level. That is, our properties focus on a trade rule's performance at that particular market and not on its implications on say, related markets or on the overall competitiveness of the affected firms. In short, we do not analyze the implications of a trade rule on the overall economy. Such an analysis seems to be an important follow-up to our work. Second, in this paper we do not consider population changes. Implications of properties such as consistency or population monotonicity (and in fact, good formulations of these ideas on this domain) remains an open question. Third, we analyze rules that are separable in total trade. We believe separability to be an intuitively desirable property and we obtain a very large class of rules that satisfy it. Nevertheless, there might be other interesting rules that violate this property.

\section{References}

[1] Barberà, S. and Jackson, M. (1995), Strategy-proof exchange. Econometrica 63:1, 51-87.

[2] Bénassy, J.P. (1982), The Economics of Market Equilibrium. Academic Press Inc.

[3] Bénassy, J.P. (1993), Nonclearing Markets: Microeconomic Concepts and Macroeconomic Applications. Journal of Economic Literature, 31, 732-761.

[4] Bénassy, J.P. (2002), The Macroeconomics of Imperfect Competition and Nonclearing Markets: A Dynamic General Equilibrium Approach. The MIT Press.

[5] Ching, S. (1992), A simple characterization of the Uniform rule. Economics Letters 40, $57-60$.

[6] Ching, S. (1994), An alternative characterization of the Uniform rule. Social Choice and Welfare 11, 131-136.

[7] Clower, R.W. (1965), The Keynesian counterrevolution: a theoretical appraisal. In The Theory of Interest Rates (F.H. Hahn and F.P.R. Brechling, eds.). Macmillan, London. 
[8] Foley, D. (1967), Resource allocation and the public sector. Yale Economic Essays 7, 45-98.

[9] Klaus B., Peters H., and Storcken T. (1997), Reallocation of an infinitely divisible good. Economic Theory 10, 305-333.

[10] Klaus B., Peters H., and Storcken T. (1998), Strategy proof division with single-peaked preferences and individual endowments. Social Choice and Welfare 15, 297-311.

[11] Kıbrıs, Ö. (2003), Constrained Allocation Problems with Single-Peaked Preferences: An Axiomatic Analysis, Social Choice and Welfare, 20:3, 353-362

[12] Leijonhufvud, A. (1968), On Keynesian economics and the economics of Keynes. Oxford University Press, London.

[13] Moulin H. (1980), On strategy-proofness and single-peakedness. Public Choice 35, 437456.

[14] Sprumont, Y. (1991), The division problem with single-peaked preferences: A characterization of the uniform rule. Econometrica 59, 509-519.

[15] Thomson, W. (1994a), Resource monotonic solutions to the problem of fair division when the preferences are single-peaked. Social Choice and Welfare 11, 205-223.

[16] Thomson, W. (1994b), Consistent solutions to the problem of fair division when the preferences are single-peaked. Journal of Economic Theory 63, 219-245.

[17] Thomson, W. (1995), Axiomatic Analysis of Generalized Economies with Single-Peaked Preferences. Mimeo. 